\title{
Glycogen metabolism is impaired in the brain of male type 2 diabetic Goto-Kakizaki
} rats

Soares, Ana Francisca; Nissen, Jakob D.; Garcia-Serrano, Alba M.; Nussbaum, Sakura S.; Waagepetersen, Helle S.; Duarte, João M.N.

\section{Published in:}

Journal of Neuroscience Research

DOI:

10.1002/jnr.24437

Publication date:

2019

Document version

Publisher's PDF, also known as Version of record

Document license:

$\mathrm{CC} B \mathrm{BY}$

Citation for published version (APA):

Soares, A. F., Nissen, J. D., Garcia-Serrano, A. M., Nussbaum, S. S., Waagepetersen, H. S., \& Duarte, J. M. N. (2019). Glycogen metabolism is impaired in the brain of male type 2 diabetic Goto-Kakizaki rats. Journal of Neuroscience Research, 97, 1004-1017. https://doi.org/10.1002/jnr.24437 


\section{gibco}

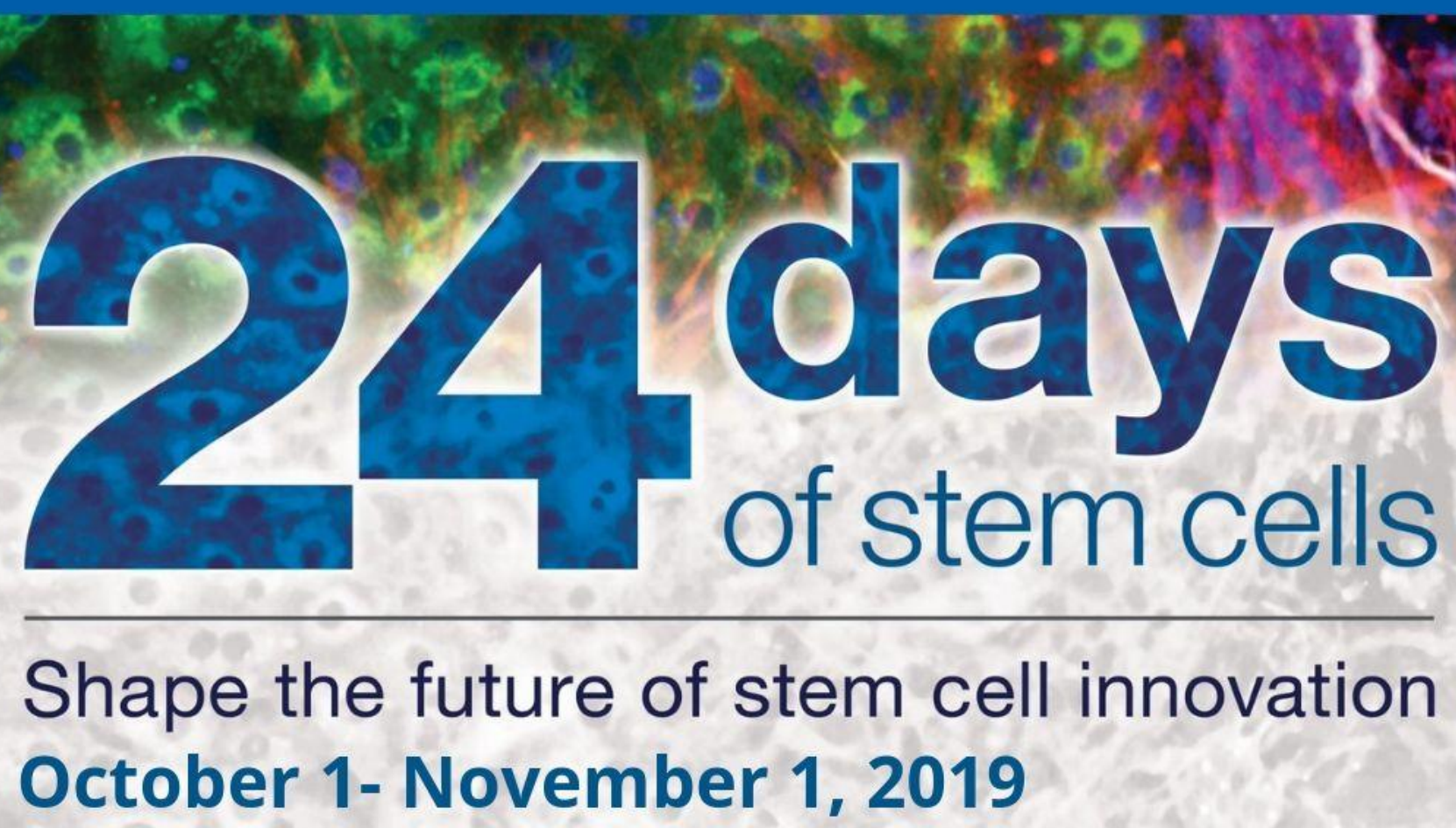

Join us for 24 Days of Stem Cells; a premiere virtual event featuring the latest advances in stem cell research.

This year's format will feature a new hour of cutting edge content every week day starting October 1st. Attend the sessions that are most relevant to your work - at your convenience and at your pace.

During the 24-day long event, you can:

- Access leading scientific presentations from thought leaders around the world

- Watch live training demonstrations from our stem cell experts

- Download key stem cell tools and resources

- Complete weekly challenges to earn points towards certification and prizes

Register today at

ThermoFisher www.24daysofstemcells.com S C I E N T I F I C 


\title{
Glycogen metabolism is impaired in the brain of male type 2 diabetic Goto-Kakizaki rats
}

\author{
Ana Francisca Soares $^{1}$ | Jakob D. Nissen ${ }^{2}$ | Alba M. Garcia-Serrano ${ }^{3,4}$ | \\ Sakura S. Nussbaum ${ }^{1}$ | Helle S. Waagepetersen ${ }^{2}$ (D) | João M. N. Duarte ${ }^{1,3,4}$ (D)
}

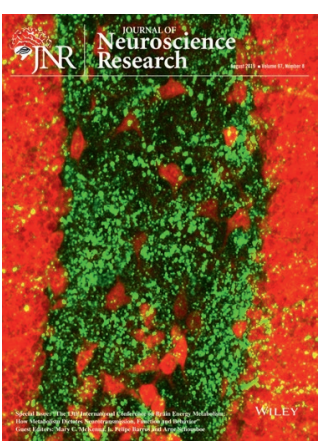

\author{
${ }^{1}$ Laboratory for Functional and Metabolic \\ Imaging, École Polytechnique Fédérale de \\ Lausanne, Lausanne, Switzerland \\ ${ }^{2}$ Faculty of Health and Medical Sciences, \\ Department of Drug Design and \\ Pharmacology, University of Copenhagen, \\ Copenhagen, Denmark \\ ${ }^{3}$ Faculty of Medicine, Department of \\ Experimental Medical Science, Lund \\ University, Lund, Sweden \\ ${ }^{4}$ Wallenberg Centre for Molecular \\ Medicine, Lund University, Lund, Sweden
}

\section{Correspondence}

João M. N. Duarte, Department of Experimental Medical Science (EMV), Lund University, BMC C11, Sölvegatan 19, 22184 Lund, Sweden.

Email: joao.duarte@med.lu.se

\section{Funding information}

This work was supported by the Knut and Alice Wallenberg Foundation, the Lundbeck Foundation (grant R165-2013-15334), the Swedish Research Council (Strategic Research Area EXODIAB, grant 2009-1039), the Swedish Foundation for Strategic Research (grant IRC15-0067), the Swiss National Science Foundation (grant 148250), and the Centre d'Imagerie BioMédicale (CIBM) of the UNIL, UNIGE, HUG, CHUV, EPFL and the Leenaards and Jeantet Foundations

\begin{abstract}
Diabetes impacts the central nervous system predisposing to cognitive decline. While glucose is the main source of energy fueling the adult brain, brain glycogen is necessary for adequate neuronal function, synaptic plasticity and memory. In this study, we tested the hypothesis that brain glycogen metabolism is impaired in type 2 diabetes (T2D). ${ }^{13} \mathrm{C}$ magnetic resonance spectroscopy (MRS) during $\left[1-{ }^{13} \mathrm{C}\right]$ glucose i.v. infusion was employed to detect ${ }^{13} \mathrm{C}$ incorporation into whole-brain glycogen in male Goto-Kakizaki (GK) rats, a lean model of T2D, and control Wistar rats. Labeling from $\left[1-{ }^{13} \mathrm{C}\right]$ glucose into brain glycogen occurred at a rate of $0.25 \pm 0.12$ and $0.48 \pm 0.22 \mu \mathrm{mol} / \mathrm{g} / \mathrm{h}$ in GK and Wistar rats, respectively $(p=0.028)$, despite similar brain glycogen concentrations. In addition, the appearance of $\left[1^{-13} \mathrm{C}\right]$ glucose in the brain was used to evaluate glucose transport and consumption. T2D caused a $31 \%$ reduction $(p=0.031)$ of the apparent maximum transport rate $\left(\mathrm{T}_{\text {max }}\right)$ and a tendency for reduced cerebral metabolic rate of glucose $\left(\mathrm{CMR}_{\mathrm{glc}}\right.$; $-29 \%, p=0.062$ ), indicating impaired glucose utilization in T2D. After MRS in vivo, gas chromatography-mass spectrometry was employed to measure regional ${ }^{13} \mathrm{C}$ fractional enrichment of glucose and glycogen in the cortex, hippocampus, striatum, and hypothalamus. The diabetes-induced reduction in glycogen labeling was most prominent in the hippocampus and hypothalamus, which are crucial for memory and energy homeostasis, respectively. These findings were further supported by changes in the phosphorylation rate of glycogen synthase, as analyzed by Western blotting. Altogether, the present results indicate that $\mathrm{T} 2 \mathrm{D}$ is associated with impaired brain glycogen metabolism.
\end{abstract}

\section{KEYWORDS}

brain metabolism, diabetes, glucose, glycogen, insulin resistance

\section{1 | INTRODUCTION}

Individuals with metabolic syndrome and type 2 diabetes (T2D) are at high risk of developing age-related cognitive decline, mild

Abbreviations: AD, Alzheimer's disease; $A \beta$, amyloid $\beta$; $B B B$, blood-brain-barrier; $\mathrm{CMR}_{\mathrm{glc}}$, cerebral metabolic rate of glucose; GC-MS, gas chromatography-mass spectrometry; GK, Goto-Kakizaki; IGF-1, insulin-like growth factor 1; ISIS, image-selected in vivo spectroscopy; $\mathrm{K}_{\mathrm{t}}$, apparent Michaelis constant for glucose transport; MRS, magnetic resonance spectroscopy; $\mathrm{T} 2 \mathrm{D}$, type 2 diabetes; $\mathrm{T}_{\max }$, apparent maximum transport rate; VOI, volume of interest. cognitive impairment, vascular dementia, and Alzheimer's disease (AD) (Baumgart et al., 2015; Duarte, 2015; Frisardi et al., 2010; Spauwen, Köhler, Verhey, Stehouwer, \& Boxtel, 2013). Indeed, AD has been proposed as an insulin resistance-associated neurodegenerative disorder, with brain alterations that resemble those observed in individuals with T2D regarding brain insulin signaling (Steculorum, Solas, \& Brüning, 2014). Insulin resistance might be directly associated to impaired cortical glucose consumption and cognitive impairment (Baker et al., 2011), and insulin signaling was proposed to 


\section{Significance}

The findings of the present study suggest that glycogen metabolism is impaired in the brain of insulin-resistant rats, which display synaptic dysfunction and memory impairment. It is known that brain glycogen is necessary to maintain proper glutamatergic neurotransmission, and it is important for certain forms of memory. Since insulin resistance has been proposed in other forms of dementia, such as Alzheimer's disease, it is plausible that glycogen metabolism is key in mediating actions of insulin in the brain.

modulate glycogen stores in astrocytes (Muhič, Vardjan, Chowdhury, Zorec, \& Kreft, 2015). However, little is known on brain glycogen metabolism in T2D. Animal models of diabetes characterized by insulin deficiency and chronic hyperglycemia do not display evident alteration of brain glycogen levels (reviewed in Duarte, 2015). On the contrary, decreased glycogen content was observed in the cerebral cortex, hippocampus, and cerebellum of Zucker diabetic fatty rats, a model of insulin resistance associated to obesity, as compared to lean littermates (Sickmann, Waagepetersen, Schousboe, Benie, \& Bouman, 2010).

Glucose entering the brain from circulation can be metabolized or stored. Glycogen is an endogenous reserve of glucose (in the form of dehydrated glucosyl units) that may reach up to $10 \mu \mathrm{mol} / \mathrm{g}$ in the rodent brain (Cruz \& Dienel, 2002; Duarte, Morgenthaler, \& Gruetter, 2017; Kong et al., 2002; Nelson, Schulz, Passonneau, \& Lowry, 1968; Swanson, Morton, Sagar, \& Sharp, 1992). Although present at an order of magnitude lower than liver or skeletal muscle, brain glycogen can be mobilized rapidly without ATP hydrolysis to support cerebral energy metabolism when fuel supply is reduced, such as upon hypoglycemia (Choi, Seaquist, \& Gruetter, 2003; Duarte et al., 2017; Herzog et al., 2008) and ischemia (Swanson, Sagar, \& Sharp, 1989). In the mature brain, glycogen is primarily located in astrocytes (Cataldo \& Broadwell, 1986). Although glucose from the blood stream is calorically sufficient to fuel brain's energetic requirements, brain glycogen stores have a prominent physiological role (Bak, Walls, Schousboe, \& Waagepetersen, 2018). It has been for a long time known to be present in astrocytic processes that are adjacent to synapses (Koizumi \& Shiraishi, 1970; Phelps, 1972). Recent work verified that glycogen occupies the finest perisynaptic processes of astrocytes (Calì et al., 2016; Oe, Baba, Ashida, Nakamura, \& Hirase, 2016). This glycogen location points toward a special role in the metabolic support to synapses. Indeed, glucose cycling through the astrocytic glycogen pool was proposed to rapidly provide the energy for neurotransmitter clearance, which would be necessary upon rapid increases of neuronal activity (Shulman, Hyder, \& Rothman, 2001). Indeed, glycogenolysis was found to be necessary for adequate glutamatergic neurotransmission in vivo (Gibbs, Lloyd, Santa, \& Hertz, 2007) and in cultured cells (Sickmann, Walls, Schousboe, Bouman, \& Waagepetersen, 2009). Accordingly, the brain isoform of glycogen phosphorylase was reported to be present in a protein complex with the most abundant high-affinity glutamate carrier, GLT-1, which is particularly enriched in small astrocytic processes near synapses (Genda et al., 2011). Given that glutamatergic neurotransmission is impaired in T2D (Girault, Sonnay, Gruetter, \& Duarte, 2019, and references there in), it is likely that brain glycogen metabolism is also perturbed. Moreover, astrocytic glycogen has been demonstrated to be necessary for synaptic plasticity, learning and memory formation (e.g., Duran, Saez, Gruart, Guinovart, \& DelgadoGarcía, 2013; Gibbs, Anderson, \& Hertz, 2006; Gibbs et al., 2007; Newman, Korol, \& Gold, 2011; Suzuki et al., 2011).

Goto-Kakizaki (GK) rats, a non-obese T2D model that was produced by selective breeding of nondiabetic Wistar rats showing poor glucose tolerance (Goto, Kakizaki, \& Masaki, 1976), are known to perform poorly in memory and learning tasks (Duarte et al., 2019; Li et al., 2013; Xiang et al., 2015). Recently, we reported that GK rats display synaptic dysfunction in the hippocampus, impaired glutamate-glutamine cycle rate, and a rearrangement of oxidative metabolism pathways that fuel brain function (Duarte et al., 2019; Girault et al., 2019). In the present study, we tested the hypothesis that brain glycogen metabolism is impaired in insulinresistant GK rats. For that, we measured labeling incorporation from $\left[1-{ }^{13} \mathrm{C}\right]$ glucose into pools of glucose and glycogen in the brain of GK and control Wistar rats, as well as brain levels of glycogen metabolizing enzymes.

\section{2 | METHODS}

\section{1 | Animals}

All procedures were performed in accordance with the Swiss federal law on animal experimentation, approved by the local committee (EXPANIM-SCAV), and reported following ARRIVE guidelines. Male GK rats (6-months old, $346 \pm 27 \mathrm{~g}, \mathrm{n}=11$ ) and Wistar rats (4-6 months old, $453 \pm 71 \mathrm{~g}, n=9$ ) from Charles River (L'Arbresle, France) were housed in pairs on a 12-hr light-dark cycle with lights on at $07: 00$, room temperature at $21-23^{\circ} \mathrm{C}$, humidity at $55 \%-60 \%$, and with tap water and food (Kliba Nafag 3436, Provimi-Kliba, Kaiseraugst, Switzerland) provided ad libitum. The present study focused on male rats due to major gender differences in the phenotype of the GK model (e.g., Desrois et al., 2004, and references therein), and because of females' differential steroid hormone profiles have an impact on the brain over the course of diabetes progression (Candeias et al., 2016). Based on previously reported variances for glycogen turnover in the rat brain (van Heeswijk, Pilloud, Morgenthaler, \& Gruetter, 2012), we estimated the sample size required for a difference between independent means at $\alpha=0.05$ and power 1- $\beta=0.9$, using G*Power version 3.1.9.2 (Faul, Erdfelder, Buchner, \& Lang, 2009). Magnetic resonance spectroscopy (MRS) experiments were conducted randomly across several weeks (2-3 experiments per week). Researchers were not blind to the rat strain during experiments in vivo. There was blinding to the origin of tissue samples during processing. 


\section{2 | MRS experiments in vivo}

Eight GK rats and six control rats were fasted overnight and anaesthetized with about $1 \%-2 \%$ isoflurane vaporized in $30 \% \mathrm{O}_{2}$ in air. Isoflurane level was regulated to maintain respiration at $50-70$ breaths per minute. Then, catheters were placed into the femoral artery and vein as previously detailed (Duarte, Carvalho, Cunha, \& Gruetter, 2009). The venal catheter was used for infusion of $\left[1-{ }^{13} \mathrm{C}\right]$ glucose (Isotec, Sigma-Aldrich, Buchs, Switzerland) prepared in phosphatebuffered saline (PBS; in mmol/L: $137 \mathrm{NaCl}, 2.7 \mathrm{KCl}, 1.5 \mathrm{KH}_{2} \mathrm{PO}_{4}, 8.1$ $\mathrm{Na}_{2} \mathrm{HPO}_{4}, \mathrm{pH}$ 7.4); and the femoral artery catheter served to collect blood samples, and to monitor heart rate and arterial blood pressure. After surgery, rats were placed in a MR compatible holder, the head was stereotaxically fixed, and the radiofrequency coil was placed on top of the head. Body temperature was continuously monitored with a rectal temperature probe (SA Instruments, Stony Brook, NY, USA) and maintained at $37^{\circ} \mathrm{C}$ with a warm water circulation system. Heart rate, blood pressure, and breathing rate were also continuously recorded with the SA Instruments monitoring system. Throughout the MRS experiment, arterial $\mathrm{pH}$, pressures of $\mathrm{CO}_{2}\left(\mathrm{P}_{\mathrm{a}} \mathrm{CO}_{2}\right)$ and $\mathrm{O}_{2}$ $\left(\mathrm{P}_{\mathrm{a}} \mathrm{O}_{2}\right)$, and haematocrit were measured with a Cobas b121 system (Roche, Rotkreuz, Switzerland), plasma glucose was measured with a Reflotron Plus system (Roche), and plasma lactate with a GM7 Micro-Stat analyser (Analox Instruments, London, UK). Additional 50- $\mu \mathrm{L}$ plasma samples were collected hourly, and stored at $-80^{\circ} \mathrm{C}$ for measurement of insulin concentration (ELISA kit \#10-1250-01 from Mercodia, Uppsala, Sweden), and for MRS analyses in vitro.

Scans in vivo were performed on a $14.1 \mathrm{~T} / 26 \mathrm{~cm}$ horizontal bore magnet (Magnex Scientific, Abingdon, UK), equipped with $12-\mathrm{cm}$ gradients $(400 \mathrm{mT} / \mathrm{m}$ in $120 \mu \mathrm{s}$ ) and interfaced to a Direct Drive console (Agilent Technologies, Palo Alto, CA, USA) using a surface coil with a ${ }^{13} \mathrm{C}$ linearly polarized loop and ${ }^{1} \mathrm{H}$ quadrature loops. Fast-spin-echo images were acquired to visualize anatomical landmarks for placement of a volume of interest (VOI) with 420-480 $\mu \mathrm{l}$ in the brain. The static magnetic field was homogenized by FAST(EST)MAP shimming, and localized ${ }^{1} \mathrm{H}$ MRS using STEAM with echo time of $2.8 \mathrm{~ms}$, repetition time of $4 \mathrm{~s}$, and mixing time of $20 \mathrm{~ms}$ was performed to determine baseline concentration of glucose in the brain (Duarte, Lanz, \& Gruetter, 2011). ${ }^{1} \mathrm{H}$ spectra were analyzed using LCModel (Stephen Provencher Inc., Oakville, ON, Canada). Localized ${ }^{13} \mathrm{C}$ MRS was performed with a modified SIRENE pulse sequence including 3D outer volume suppression, 1D inversion nulling, 1D Image-Selected In vivo Spectroscopy (ISIS) module, and bilevel Waltz-16 nuclear Overhauser effect (NOE) and decoupling (van Heeswijk et al., 2012). Spectra were sequentially recorded with 128 scans and repetition time of $1 \mathrm{~s}$ for at least $9 \mathrm{hr}$. During ${ }^{13} \mathrm{C}$ MRS, $\left[1-{ }^{13} \mathrm{C}\right]$ glucose $(1.1 \mathrm{mmol} / \mathrm{L})$ was administered as a bolus with $99.9 \%$ enrichment, followed by continuous infusion with a 70\%-enriched solution (Duarte et al., 2011). Peak areas of ${ }^{13} \mathrm{C}$ spectra were quantified by line-fitting in NUTS (Acorn NMR, Livermore, CA USA). Glucose C1 was quantified from each recorded spectrum (128 scans), while glycogen C1 was quantified from the sum of 32 spectra (4,096 scans), resulting in temporal resolutions of 2.1 and $68.3 \mathrm{~min}$, respectively.

\section{3 | Brain tissue processing}

After ${ }^{13} \mathrm{C}$ MRS, rats were immediately sacrificed with a focused microwave fixation device irradiating the brain for $2.3 \mathrm{~s}$ at $4 \mathrm{~kW}$ and 2,450 MHz (Gerling Applied Engineering, Modesto, CA, USA). The cerebrum was rapidly taken out of the skull and dissected. The hypothalamus, which was not comprised in the VOI for ${ }^{13} \mathrm{C}$ MRS, was dissected and stored. The cortex, hippocampus, and striatum were collected from one hemisphere to investigate regional variations of glycogen metabolism. The other hemisphere was stored to allow scaling the whole-brain ${ }^{13} \mathrm{C}$ enrichment curves measured in vivo to absolute concentration of glucose and glycogen. All samples were immediately stored at $-80^{\circ} \mathrm{C}$ until further processing.

Frozen samples were powdered with a mortar and pestle in liquid $\mathrm{N}_{2}$, homogenized in $30 \mathrm{mmol} / \mathrm{L} \mathrm{HCl}$ with an ultrasonic homogenizer Sonopuls HD 2070 with the microtip MS 73 (Bandelin, Berlin, Germany), and then boiled for $45 \mathrm{~min}$ at $90^{\circ} \mathrm{C}$. After adjusting the $\mathrm{pH}$ to 5 with sodium acetate, samples and standards of glycogen (glycogen from oyster Type II, Sigma-Aldrich) were incubated in the presence or absence of $30 \mathrm{ng} / \mathrm{ml}$ amylo- $\alpha-1,4-\alpha-1,6$-glucosidase (Roche) for $2 \mathrm{hr}$ at $37^{\circ} \mathrm{C}$ (Duarte et al., 2017). After enzymatic digestion, pH was adjusted to 7. Samples were then centrifuged at 14,000 g for $15 \mathrm{~min}$, and supernatants were collected for lyophilization.

\section{4 | MRS in vitro}

After processing, extracts from the whole hemisphere were lyophilized and then re-dissolved in ${ }^{2} \mathrm{H}_{2} \mathrm{O}\left(99.9 \%{ }^{2} \mathrm{H}\right.$, Sigma-Aldrich). Plasma samples were diluted 1:20 in ${ }^{2} \mathrm{H}_{2} \mathrm{O}$. After adding sodium fumarate $(1.2 \mu \mathrm{mol})$ as internal standard, water-suppressed ${ }^{1} \mathrm{H}$ MRS was performed as previously detailed (Duarte, Cunha, \& Carvalho, 2007) on a DRX-600 spectrometer equipped with a 5-mm cryoprobe (Bruker BioSpin SA, Fallanden, Switzerland). In each sample, $\left[{ }^{12} \mathrm{C}\right]$ glucose was determined from the ${ }^{1} \mathrm{H}$ resonance of $\alpha$-glucose that consists of a doublet at $5.22 \mathrm{ppm}$, and $\left[1{ }^{13} \mathrm{C}\right]$ glucose was determined from the resonances arising from heteronuclear ${ }^{1} \mathrm{H}-{ }^{13} \mathrm{C}$ coupling $\left(J_{\mathrm{HC}}=184.5 \mathrm{~Hz}\right)$, which appear as satellites of the central $\alpha$-glucose $\mathrm{H} 1$ doublet at $5.22 \mathrm{ppm}$.

Concentrations of unlabeled glucose and $\left[1-{ }^{13} \mathrm{C}\right]$ glucose were determined in ${ }^{1} \mathrm{H}$ spectra of non-digested extracts of the whole hemisphere. These concentrations were subtracted from those in spectra of digested extracts to determine the concentrations of unlabeled glycogen and $\left[1{ }^{13} \mathrm{C}\right]$ glycogen in the brain. The concentrations of $\left[1-{ }^{13} \mathrm{C}\right]$ glucose and $\left[1-{ }^{13} \mathrm{C}\right]$ glycogen served to scale ${ }^{13} \mathrm{C}$ labeling curves detected in vivo.

\subsection{Analysis of glucose and glycogen metabolism}

Glycogen concentrations were reported in terms of glucosyl equivalents released after amylo- $\alpha-1,4-\alpha-1,6$-glucosidase digestion. Absolute concentrations of $\left[1-{ }^{13} \mathrm{C}\right]$ glucose and $\left[1-{ }^{13} \mathrm{C}\right]$ glycogen in the whole-brain hemisphere were used to scale ${ }^{13} \mathrm{C}$ signal areas measured in vivo during the ${ }^{13} \mathrm{C}$ MRS experiment. Plasma glucose $\left(\mathrm{Gl}_{\text {plasma }}\right)$ was assumed to be transported into the brain with a 
reversible Michaelis-Menten kinetics as previously described for the rat brain (Duarte et al., 2011). Therefore, brain glucose $\left(\mathrm{Gl}_{\mathrm{brain}}\right)$ is defined by:

$$
\frac{\mathrm{dGlc}_{\text {brain }}}{\mathrm{dt}}=\mathrm{T}_{\text {max }} \frac{\mathrm{Glc}_{\text {plasma }}-\mathrm{Glc}_{\mathrm{brain}} / \mathrm{v}_{\mathrm{d}}}{\mathrm{Glc}_{\text {plasma }}+\mathrm{Glc}_{\text {brain }} / \mathrm{v}_{\mathrm{d}}+\mathrm{K}_{\mathrm{t}}}-\mathrm{CMR}_{\mathrm{glc}} \text {, }
$$

where $T_{\max }$ is the apparent maximal transport rate, $\mathrm{K}_{\mathrm{t}}$ is the apparent Michaelis constant for glucose transport, $\mathrm{CMR}_{\mathrm{glc}}$ is the cerebral metabolic rate of glucose consumption, and $V_{d}$ is the physical volume for glucose distribution in the brain $(0.77 \mathrm{ml} / \mathrm{g})$. Similarly, for $\left[1-{ }^{13} \mathrm{C}\right]$ glucose, transport is defined by
Processed extracts from the hypothalamus, cortex, hippocampus, and striatum were lyophilized and subsequently derivatized and analyzed by GC-MS to establish ${ }^{13} \mathrm{C}$-labeling in glycogen-derived glucose using a method adapted and modified from Jackson, Waterhouse, and Bluck (2007). Glucose butylboronate derivatives were prepared by adding $100 \mu \mathrm{l}$ of a $10 \mathrm{mg} / \mathrm{ml}$ solution of 1-butylboronic (SigmalAldrich) acid in pyridine (Sigma-Aldrich) to a maximum of $50 \mu \mathrm{g}$ of ${ }^{12} \mathrm{C}$-glucose (Sigma-Aldrich) (standards) or the fully dried extracts containing a minimum of $1 \mu \mathrm{g}$ of glucose. Subsequently, the resulting mixtures were whirl-mixed, spun down, and heated at $80^{\circ} \mathrm{C}$ for $1 \mathrm{hr}$. The derivatization was completed by the addition of $10 \mu \mathrm{l}$ of acetic anhydride (Sigma-Aldrich) to the cooled pyridine-mixture, whirl-mixing, and

$\frac{\mathrm{d}\left[1-{ }^{13} \mathrm{C}\right] \mathrm{Glc}_{\text {brain }}}{\mathrm{dt}}=\mathrm{T}_{\max } \frac{\left[1-{ }^{13} \mathrm{C}\right] \mathrm{Gl} \mathrm{c}_{\text {plasma }}-\left[1-{ }^{13} \mathrm{C}\right] \mathrm{Gl} \mathrm{c}_{\text {brain }} / \mathrm{V}_{\mathrm{d}}}{\mathrm{Glc}_{\text {plasma }}+\mathrm{Glc}_{\text {brain }} / \mathrm{V}_{\mathrm{d}}+\mathrm{K}_{\mathrm{t}}}-\mathrm{CMR}_{\mathrm{glc}} \frac{\left[1-{ }^{13} \mathrm{C}\right] \mathrm{Gl} \mathrm{c}_{\text {brain }}}{\mathrm{Glc}_{\text {brain }}}$.

As detailed previously (Duarte et al., 2011), Equations 1 and 2 were fitted to the concentration of $\left[1-{ }^{13} \mathrm{C}\right]$ glucose in the brain as a function of total glucose and $\left[1-{ }^{13} \mathrm{C}\right]$ glucose in plasma, and allowed determining $\mathrm{T}_{\text {max }}, \mathrm{CMR}_{\mathrm{glc}}$, and $\mathrm{K}_{\mathrm{t}}$.

For the analysis of glycogen metabolism, we assumed that variations of glycogen concentration during the experiment are negligible (Duarte et al., 2017; Morgenthaler, Koski, Kraftsik, Henry, \& Gruetter, 2006), implying that synthesis and degradation fluxes are equal $\left(\mathrm{V}_{\text {glyc }}\right)$; and that glycolysis does not influence glycogen labeling rate because $\mathrm{V}_{\text {glyc }}{ } \mathrm{CMR}_{\mathrm{glc}}$ (Morgenthaler et al., 2009), and thus labeling of glucose resembles that of brain glucose-6-phosphate, from which glycogen is synthetized. Therefore, the rate of glycogen labeling is given by

$$
\frac{\mathrm{d}\left[1-{ }^{13} \mathrm{C}\right] \mathrm{Glycogen}}{\mathrm{dt}}=\mathrm{V}_{\text {glyc }}\left(\frac{\left[1-{ }^{13} \mathrm{C}\right] \mathrm{Glc}}{\mathrm{Glc}}-\frac{\left[1-{ }^{13} \mathrm{C}\right] \mathrm{Glycogen}}{\text { Glycogen }}\right) .
$$

This equation was fitted to the curve of $\left[1{ }^{13} \mathrm{C}\right]$ glycogen with $\left[1-{ }^{13} \mathrm{C}\right] \mathrm{Glc}$ and Glc obtained using Equations 1 and 2. The turnover time of glycogen $(\tau)$, i.e., the time required to replace all the glucosyl units, is obtained by dividing brain glycogen content by $\mathrm{V}_{\text {glyc }}$.

\subsection{Enzymatic determination of glucose and gas chromatography-mass spectrometry (GC-MS) analysis}

Glucose concentration in processed extracts from the hypothalamus, cortex, hippocampus, and striatum was determined by the glucose oxidase method coupled to a peroxidase reaction to colorimetrically detect $\mathrm{H}_{2} \mathrm{O}_{2}$ formation (Duarte et al., 2017). Briefly, samples and glucose standards were diluted in $50 \mathrm{mmol} / \mathrm{L}$ sodium phosphate buffer ( $\mathrm{pH} 7.4)$ and incubated in the presence of $2 \mathrm{U} / \mathrm{ml}$ glucose oxidase (Sigma-Aldrich), $0.2 \mathrm{U} / \mathrm{ml}$ horseradish peroxidase (Sigma-Aldrich) and $100 \mu \mathrm{mol} / \mathrm{L}$ AmplexRed (Invitrogen, Basel, Switzerland) for $30 \mathrm{~min}$ in the dark. Resorufin, the product of AmplexRed oxidation, was detected at $560 \mathrm{~nm}$ with a PowerWave XS microplate spectrophotometer (BioTek, Luzern, Switzerland). Glycogen concentration was reported in terms of glucosyl equivalents released after amylo- $\alpha-1,4-\alpha-1,6$-glucosidase digestion, and normalized to the tissue's wet weight. heating at $80^{\circ} \mathrm{C}$ for $1 \mathrm{hr}$. The samples were subsequently dried under nitrogen at $60^{\circ} \mathrm{C}$, and the residue taken up in $100 \mu \mathrm{l}$ of trimethylpentane (Sigma-Aldrich) containing $1 \%$ of acetic anhydride for stabilization. The samples were transferred to inserts and run on GC-MS using an Agilent Technologies 7820A chromatograph (Agilent J\&W GC column HP-5MS, parts no. 19091S-433) coupled to Agilent Technologies 5977E mass spectrometer. Isotopic enrichment was corrected for natural abundance of ${ }^{13} \mathrm{C}$ in the standards and natural abundance of ${ }^{10} \mathrm{~B}$ in the derivatization agent, and calculated according to Biemann (1962) and Walls, Bak, Sonnewald, Schousboe, and Waagepetersen (2014).

\section{7 | Western blotting}

Rats ( $n=3$ from each strain) were briefly anesthetized with isoflurane (3.5\% in air) before being killed by decapitation. The brain was rapidly removed and brain regions dissected in ice-cold PBS. Tissue samples were homogenized with a needle sonicator in lysis buffer [in mmol/L: $150 \mathrm{NaCl}, 1$ ethylenediaminetetraacetic acid (EDTA), 50 tris(hydroxymethyl)aminomethane (Tris)- $\mathrm{HCl}, 1 \%$ (v/v) Triton X-100, $0.5 \%(\mathrm{w} / \mathrm{v})$ sodium deoxycholate, $0.5 \%(\mathrm{w} / \mathrm{v})$ sodium dodecylsulfate (SDS), $\mathrm{pH}$ 8.0] containing phosphatase and protease inhibitors (Roche, Switzerland). The homogenate was then maintained in constant agitation for $2 \mathrm{hr}$ at $4^{\circ} \mathrm{C}$. After centrifugation at $3,000 \mathrm{~g}$ for $10 \mathrm{~min}$ at $4^{\circ} \mathrm{C}$ to remove major debris, the supernatant was saved. Total protein content was determined with the bicinchoninic acid assay from Pierce (Thermo Fisher Scientific, Göteborg, Sweden).

Samples were then diluted in sample buffer (in mmol/L: 141 Trisbase, 106 Tris- $\mathrm{HCl}, 50$ dithiothreitol, 0.51 EDTA, 0.22 Coomassie Brilliant Blue G-250, 0.175 Phenol Red; 2\% (w/v) lithium dodecylsulfate, $10 \%$ Glycerol, $\mathrm{pH} 8.5$ ), 40 or $100 \mu \mathrm{g}$ of protein were loaded in precast NuPAGE Novex $4 \%-12 \%$ polyacrylamide gradient gels (Invitrogen, Thermo Fisher Scientific) along with molecular weight standards (Precision Plus Protein standards from BioRad, Sundbyberg, Sweden), and electrophoresis was carried out at with at $125 \mathrm{~V}$ in a 3-(N-morpholino)propanesulfonic acid (MOPS) running buffer (in mmol/L: 50 MOPS, 50 Tris Base, 1 EDTA, 0.1\% SDS, pH 7.7). 
Proteins were transferred onto $0.45 \mu \mathrm{m}$ polyvinylidene difluoride membranes (GE Life Sciences, Sweden) in a buffer composed of $39 \mathrm{mmol} / \mathrm{L}$ glycine, $48 \mathrm{mmol} / \mathrm{L}$ Tris and 20\% (v/v) methanol (pH 9.2). The membranes were subsequently blocked for $90 \mathrm{~min}$ in $5 \%(\mathrm{w} / \mathrm{v})$ bovine serum albumin solution prepared in Tris-buffered saline (in mmol/L: 50 Tris, $150 \mathrm{NaCl}$, pH 7.4) with 0.1\% (v/v) tween-20 (TBS-T), and then were incubated with primary antibodies diluted in the blocking solution at $1: 1,000$ were incubated at $4{ }^{\circ} \mathrm{C}$ overnight. Antibodies against glycogen synthase (\#3886; RRID:AB_2116392; clone 15B1; raised in rabbit) and phospho(Ser641)-glycogen synthase (\#3891; RRID:AB_2116390; produced in rabbit) were purchased from Cell Signaling (Leiden, The Netherlands). Antibodies against glycogen phosphatase brain and muscle isoforms (produced in chicken and guinea pig, respectively) were developed and characterized by the Metabolic Engineering and Diabetes Therapy Lab (Duran et al., 2013; Sinadinos et al., 2014) and kindly provided by Jordi Duran (IRB Barcelona, Spain). Rabbit antiserum against the C-terminal region of glucose transporter 1 (GLUT1; Holman et al., 1990) was kindly provided by Samuel W. Cushman (National Institutes of Health, USA). After three washes in TBS-T containing 1\% BSA, membranes were incubated with the respective horseradish peroxidase-conjugated antibodies: goat anti-rabbit IgG (\#ab6721, AbCam, Cambridge, UK; RRID:AB_955447), rabbit anti-chicken IgG (\#AP162P, MerckMillipore, Darmstadt, Germany; RRID:AB_11212232), or goat antiguinea pig IgG (\#AP108P, Merck-Millipore; RRID:AB_11211870) for $1 \mathrm{~h}$ at room temperature. After three more washes, the membranes were developed in the ChemiDoc (BioRad) using the SuperSignal West Pico PLUS Chemiluminiscent substrate (Thermo Scientific). All membranes were then re-probed for $\beta$-actin (clone AC15, produced in mouse; \#ab6276, AbCam; RRID:AB_2223210; secondary antibody was goat anti-mouse IgG, \#ab6789, AbCam; RRID:AB_955439) to confirm that similar protein content was loaded in each gel lane.

\subsection{Statistics}

Statistical analyses were performed using Prism 8.0.1 (GraphPad, San Diego, California, USA). Results are shown as mean \pm SD. Data were assumed to follow normality, linearity, and equality of variance. Significant differences between GK and Wistar rat groups were considered for $p<0.05$ on Student $t$ tests. Two-way ANOVA was applied to compare glycogen and glucose concentrations and labeling originating from multiple brain areas, and the Holm-Sidak's test was used for post hoc multiple comparisons.

\section{3 | RESULTS}

\section{1 | Glycogen metabolism}

Baseline plasma glucose measured before MRS was $10.4 \pm 1.2 \mathrm{mmol} / \mathrm{L}$ in GK rats and $5.5 \pm 0.9 \mathrm{mmol} / \mathrm{L}$ in controls $(p<0.001)$. Brain glucose content measured by ${ }^{1} \mathrm{H}$ MRS in vivo before $\left[1-{ }^{13} \mathrm{C}\right]$ glucose infusion, was $1.4 \pm 0.5 \mu \mathrm{mol} / \mathrm{g}$ in GK rats and $0.8 \pm 0.4 \mu \mathrm{mol} / \mathrm{g}$ in Wistar rats $(p=0.006)$.
Animals were maintained on free breathing, and GK rats required lower mean isoflurane levels than Wistar rats $(1.0 \pm 0.1 \%$ vs. $1.4 \pm 0.1 \%, p<0.001$ ) to achieve similar respiration rates (Table 1 ). Although physiology parameters were maintained within the normal range across the whole experimental protocol under isoflurane anesthesia, there were some differences between the two groups (Table 1). Namely, relative to controls, GK rats displayed significantly lower $\mathrm{P}_{\mathrm{a}} \mathrm{CO}_{2}(-11 \%, p=0.031)$. Given their insulin resistance, $\mathrm{GK}$ rats required slower glucose infusion rate than controls to achieve similar glycaemia $(-43 \%, p=0.004)$. Since less $\left[1-{ }^{13} \mathrm{C}\right]$ glucose solution is administered, GK rats displayed slightly larger hematocrit than controls $(+9 \%, p=0.024)$ without changes in total hemoglobin content. Moreover, consistent with the slower glucose disposal rate, GK rats had lower circulating lactate levels than controls $(-61 \%, p<0.001)$. Insulin concentration in circulation increased upon glucose administration, and was similar in GK and Wistar rats.

In Wistar rats, the fractional enrichment (FE) of plasma glucose was stable throughout the infusion protocol, reaching $0.61 \pm 0.05$ at the end of the ${ }^{13} \mathrm{C}$ experiment (Figure $1 \mathrm{~b}$ ). On the contrary, the FE of plasma glucose in GK was below that of Wistar, and reached $0.46 \pm 0.06$ at the end ( $p<0.001$ vs. Wistar). In agreement, FE of glucose in the brain extracts was also lower in GK when compared to Wistar rats $(0.42 \pm 0.09$ vs. $0.57 \pm 0.06, p<0.003)$.

TAB LE 1 Mean physiology parameters across the MRS protocol

\begin{tabular}{|c|c|c|c|}
\hline & Wistar $(n=6)$ & $\mathrm{GK}(n=8)$ & $p$ values \\
\hline Temperature $\left({ }^{\circ} \mathrm{C}\right)$ & $37.4 \pm 0.2$ & $37.6 \pm 0.6$ & 0.451 \\
\hline $\begin{array}{l}\text { Respiration rate } \\
\text { (breaths/minute) }\end{array}$ & $64 \pm 7$ & $58 \pm 3$ & 0.072 \\
\hline $\begin{array}{l}\text { Heart rate (beats/ } \\
\text { minute) }\end{array}$ & $406 \pm 37$ & $352 \pm 88$ & 0.185 \\
\hline \multicolumn{4}{|c|}{ Blood pressure (mm Hg) } \\
\hline Systole & $162 \pm 56$ & $166 \pm 62$ & 0.901 \\
\hline Dyastole & $103 \pm 61$ & $100 \pm 79$ & 0.887 \\
\hline Saturation $\mathrm{O}_{2}(\%)$ & $95.5 \pm 2.4$ & $96.5 \pm 4.0$ & 0.600 \\
\hline $\begin{array}{l}\text { Total hemoglobin } \\
\text { (g/dl) }\end{array}$ & $14.8 \pm 1.2$ & $15.0 \pm 0.8$ & 0.772 \\
\hline Hematocrit (\%) & $34.6 \pm 2.2$ & $37.6 \pm 2.3$ & 0.024 \\
\hline $\mathrm{pH}$ & $7.36 \pm 0.02$ & $7.39 \pm 0.03$ & 0.069 \\
\hline $\mathrm{P}_{\mathrm{a}} \mathrm{CO}_{2}(\mathrm{~mm} \mathrm{Hg})$ & $41.2 \pm 3.7$ & $36.8 \pm 2.8$ & 0.031 \\
\hline $\mathrm{P}_{\mathrm{a}} \mathrm{O}_{2}(\mathrm{~mm} \mathrm{Hg})$ & $187 \pm 49$ & $221 \pm 99$ & 0.457 \\
\hline $\mathrm{HCO}_{3}^{-}(\mathrm{mmol} / \mathrm{L})$ & $22.7 \pm 1.0$ & $21.6 \pm 1.7$ & 0.123 \\
\hline \multicolumn{4}{|c|}{ Insulin concentration $(\mu \mathrm{g} / \mathrm{L})$} \\
\hline Baseline & $0.24 \pm 0.20$ & $0.23 \pm 0.05$ & 0.942 \\
\hline During infusion & $1.76 \pm 1.40$ & $1.69 \pm 1.12$ & 0.917 \\
\hline \multicolumn{4}{|c|}{ Lactate concentration (mmol/L) } \\
\hline Baseline & $0.94 \pm 0.22$ & $0.91 \pm 0.34$ & 0.840 \\
\hline During infusion & $3.15 \pm 0.51$ & $1.24 \pm 0.31$ & $<0.001$ \\
\hline $\begin{array}{l}\text { Glucose disposal } \\
\text { rate }(\mathrm{g} / \mathrm{kg} / \mathrm{h})\end{array}$ & $1.42 \pm 0.32$ & $0.81 \pm 0.34$ & 0.004 \\
\hline
\end{tabular}

$p$ values result from comparisons using two-tailed Student $t$ tests. 
(a)

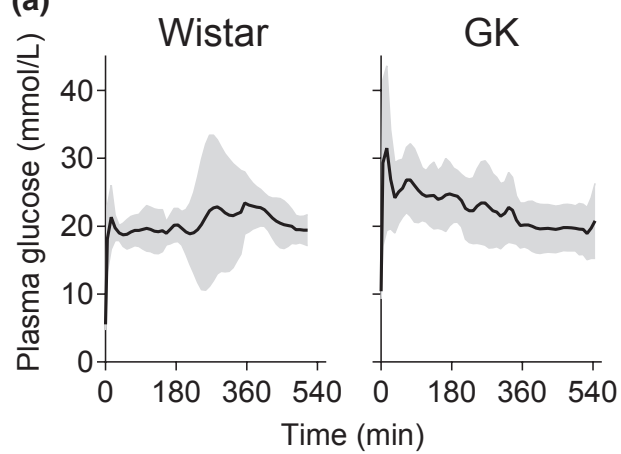

(b)

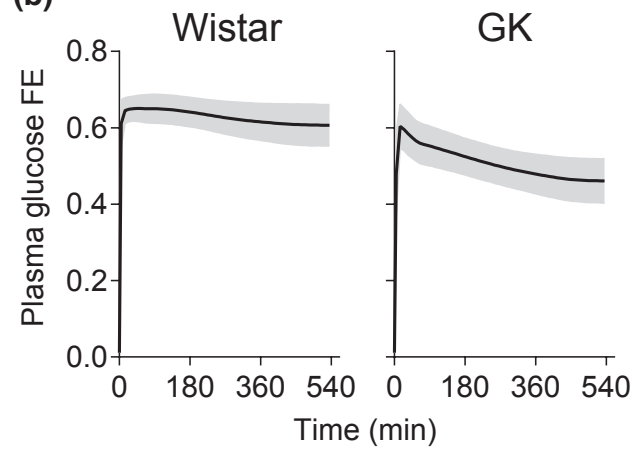

FIGURE 1 Plasma glucose concentration (a) and FE (b) in Wistar $(n=6)$ and GK $(n=8)$ rats during $\left[1-{ }^{13} \mathrm{C}\right]$ glucose infusion. The trace and shaded area are the mean and $S D$, respectively

At the end of the glucose infusion protocol, whole-brain glucose concentration (determined in tissue extracts), was $4.4 \pm 0.8 \mu \mathrm{mol} / \mathrm{g}$ in GK rats and $4.2 \pm 1.6 \mu \mathrm{mol} / \mathrm{g}$ in Wistar rats $(p=0.794)$. Wholebrain glycogen concentration was also similar in the two groups: $5.0 \pm 1.1 \mu \mathrm{mol} / \mathrm{g}$ in GK rats and $5.5 \pm 2.3 \mu \mathrm{mol} / \mathrm{g}$ in Wistar rats ( $p=0.681$ ). Like for labeling of plasma and brain glucose, brain glycogen FE was lower in GK than Wistar rats $(0.14 \pm 0.02$ vs. $0.24 \pm 0.07$, $p=0.004)$.

The labeling of brain $\left[1-{ }^{13} \mathrm{C}\right]$ glucose and $\left[1-{ }^{13} \mathrm{C}\right]$ glycogen was detected in real time by ${ }^{13} \mathrm{C}$ MRS (Figure 2). Glucose ${ }^{13} \mathrm{C}$ signals from $\alpha$ and $\beta$ anomeres were quantified in each spectrum (128 scans), that is at a temporal resolution of about $2 \mathrm{~min}$. In contrast, given the slow turnover of glycogen and its naturally wider linewidth, 32 spectra were summed for accurate quantification of its ${ }^{13} \mathrm{C}$ signal area at $100.5 \mathrm{ppm}$.

Figure 3 shows typical curves of glucose concentration and ${ }^{13} \mathrm{C}$ labeling in plasma, as well as brain $\left[1-{ }^{13} \mathrm{C}\right]$ glucose, in one $\mathrm{GK}$ and one Wistar rat during the ${ }^{13} \mathrm{C}$ MRS experiment. Glucose transport and consumption rates were estimated from these curves. $\mathrm{T}_{\max }$ was $1.14 \pm 0.22$ and $0.78 \pm 0.30 \mu \mathrm{mol} / \mathrm{g} / \mathrm{min}(p=0.031), \mathrm{K}_{\mathrm{t}}$ was $0.9 \pm 1.0$ and $1.4 \pm 2.1 \mathrm{mM}(p=0.625)$, and $\mathrm{CMR}_{\mathrm{glc}}$ was $0.65 \pm 0.13$ and $0.46 \pm 0.21 \mu \mathrm{mol} / \mathrm{g} / \mathrm{min}(p=0.062)$ in Wistar and GK rats, respectively. Interestingly, this resulted in similar ratio of $\mathrm{T}_{\max }$ to $\mathrm{CMR}_{\mathrm{glc}}$ : $1.8 \pm 0.4$ in controls and $1.8 \pm 0.8$ in GK rats $(p=0.763)$, suggesting that the relation of brain to plasma glucose levels is not changed in diabetic GK rats.

Labeling of brain glycogen from $\left[1-{ }^{13} \mathrm{C}\right]$ glucose was slower in GK than Wistar rats (Figure 4). The rate of glycogen synthesis $\left(\mathrm{V}_{\text {glyc }}\right)$, which was two orders of magnitude slower than $\mathrm{CMR}_{\mathrm{glc}}$, was $0.004 \pm 0.002$ and $0.008 \pm 0.004 \mu \mathrm{mol} / \mathrm{g} / \mathrm{min}$ in GK and Wistar rats, respectively $(p=0.028)$. In $\mu \mathrm{mol} / \mathrm{g} / \mathrm{h}, \mathrm{V}_{\text {glyc }}$ was $0.25 \pm 0.12$ in $\mathrm{GK}$ rats and $0.48 \pm 0.22$ in controls. Taking in account brain glycogen concentration, glycogen turnover time $\tau$ was $26.6 \pm 13.6 \mathrm{hr}$ in GK rats and $14.4 \pm 4.2 \mathrm{hr}$ in Wistar rats $(p=0.041)$.

\section{2 | Regional glycogen labeling}

We further investigated the regional distribution of glycogen in the brain (Figure 5a). Diabetes affected brain glycogen concentration

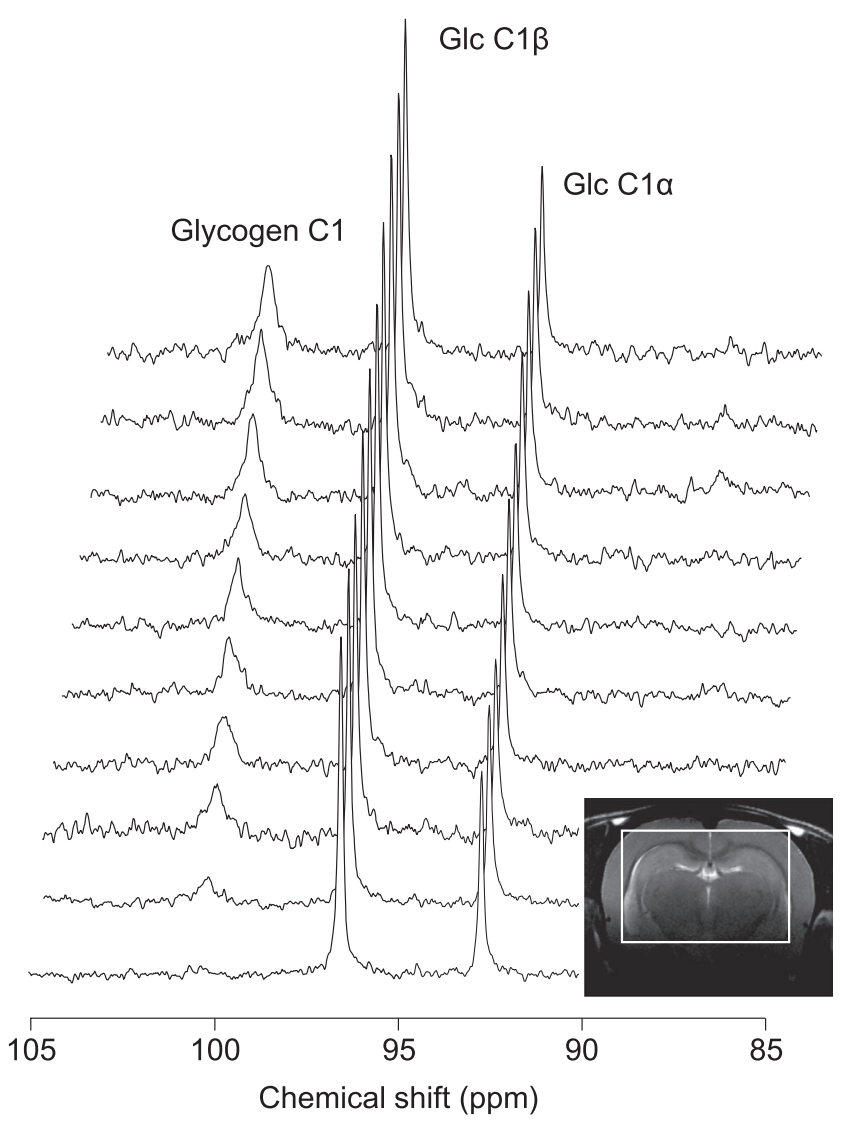

FIGURE 2 Typical ${ }^{13} \mathrm{C}$ spectra acquired in vivo in the rat brain upon infusion of $\left[1-{ }^{13} \mathrm{C}\right]$ glucose. Each spectrum is the accumulation of 4,096 scans (68 min). Lorentzian line broadening of $10 \mathrm{~Hz}$ was applied prior to Fourier transformation. The inset rat brain image shows the typical location of the VOI used for ${ }^{13} \mathrm{C}$ MRS

$\left(F_{1,48}=13.4, p=0.001\right)$ and there was also a significant effect of brain region $\left(F_{3,48}=7.1, p<0.001\right)$, but no interaction $\left(F_{3,48}=2.5\right.$, $p=0.062)$. Posttests revealed reduced glycogen in the striatum of GK rats compared to controls $(-44 \%, p=0.001)$. Diabetes also affected brain glucose concentration $\left(F_{1,48}=11.8, p=0.001\right)$, and there was a brain region effect $\left(F_{3,48}=3.5, p=0.020\right.$; interaction $\left.F_{3,48}=1.7, p=0.178\right)$. Upon post hoc testing, the reduction of 
(a)

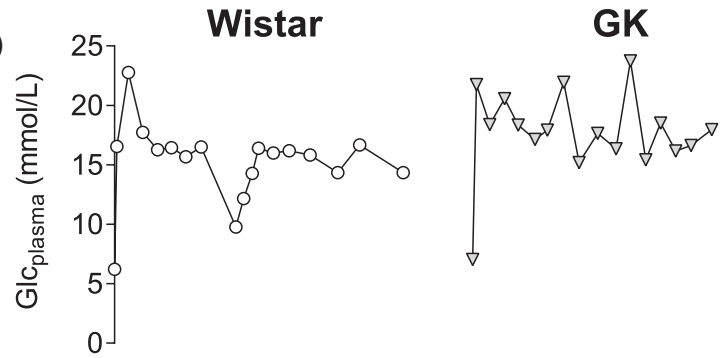

(b)

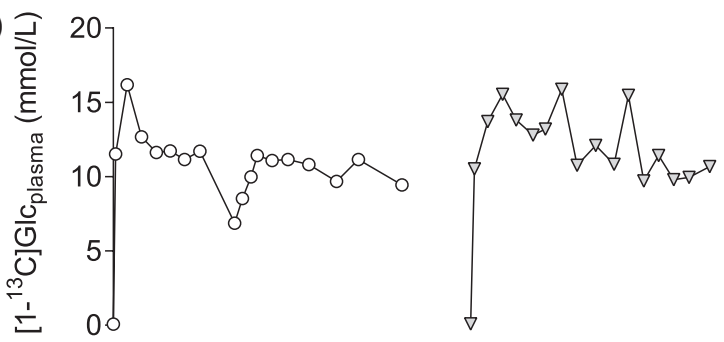

(c)

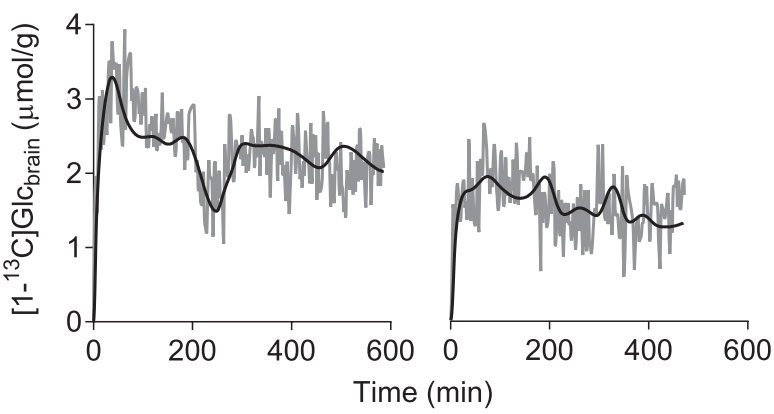

FIGURE 3 Typical fit of brain $\left[1-{ }^{13} \mathrm{C}\right]$ glucose time courses $\left(\left[1{ }^{13} \mathrm{C}\right] \mathrm{Gl} \mathrm{c}_{\text {brain }}\right)$ as function of plasma glucose $\left(\mathrm{Glc}_{\text {plasma }}\right)$ concentration (a) and ${ }^{13} \mathrm{C}$ labeled $\mathrm{Glc}_{\text {plasma }}$ (b). In the particular cases of this figure, best fit in panel c resulted in $\mathrm{T}_{\max }$ was 1.37 and $0.92 \mu \mathrm{mol} / \mathrm{g} / \mathrm{min}$ and $\mathrm{CMR}_{\mathrm{glc}}$ was 0.77 and $0.65 \mu \mathrm{mol} / \mathrm{g} / \mathrm{min}$ for Wistar and GK rats, respectively

glucose concentration was significant in the cortex $(-37 \% \mathrm{vs}$. Wistar, $p=0.047)$ and striatum $(-37 \%$ vs. Wistar, $p=0.010)$.

Whole-brain glycogen turnover was reduced in the brain of GK rats, compared to controls, which resulted in reduced brain glycogen enrichment at the end of the $\left[1-{ }^{13} \mathrm{C}\right]$ glucose infusion. In turn, when investigating ${ }^{13} \mathrm{C}$ labeling in extracts from specific brain areas by GC-MS, we observed significant effects of diabetes $\left(F_{1,48}=50.4, p<0.001\right)$ and brain region $\left(F_{3,48}=17.0, p<0.001\right)$, but no interaction $\left(F_{3,48}<0.1, p=0.979\right)$. In particular, there was a reduction of glycogen ${ }^{13} \mathrm{C}$ enrichment of $33 \%$ in the hypothalamus $(p=0.002), 29 \%$ in the hippocampus ( $p=0.002), 25 \%$ in the striatum ( $p=0.002)$, and $24 \%$ in the cortex $(p=0.002)$ of GK rats, relative to Wistar rats (Figure $5 \mathrm{~b}$ ). Since ${ }^{13} \mathrm{C}$ labeling of glucose in these brain areas was about $21 \%-22 \%$ lower in GK than controls $(p<0.001$ for all posttests), we infer that the diabetes-induced reduction of glycogen labeling was most prominent in the hypothalamus and hippocampus.

\section{3 | GLUT1 and glycogen metabolizing enzymes}

Since glucose uptake from the blood stream is primarily mediated by GLUT1, the density of the glucose carrier GLUT 1 was analyzed by Western blot (Figure 6a), which detected the two glycosylation forms that are specifically present in endothelial cells (55 kDa) and brain parenchyma (45 kDa) (Simpson, Carruthers, \& Vannucci, 2007). The immunoreactivity of GLUT1 in the striatum and cortex was similar between GK and Wistar rats. In the hypothalamus, there was a significant T2D-induced reduction of the $55 \mathrm{kDa}(-41 \%, p=0.041)$ form of GLUT1. GK rats had significantly lower 45 kDa GLUT1 immunoreactivity in the hippocampus, when compared to controls $(-19 \%, p=0.030)$.

Glycogen concentration is directly dependent on the activities of glycogen synthase and glycogen phosphorylase. The density of both muscle and brain isoforms of glycogen phosphorylase was similar in GK rats and controls (Figure 6b,c). Glycogen synthase levels were affected by diabetes. Namely, we observed a $21 \%$ reduction in the density of glycogen synthase in the hippocampus of GK rats, relative to controls ( $p=0.015$; Figure $6 \mathrm{~d}$ ). Moreover, we measured the density of phospho-glycogen synthase at the phosphorylation sites Ser460 and Ser641. The level of phospho-glycogen synthase in the cortex was significantly higher in GK than Wistar rats $(+57 \%$, $p=0.027$, Figure 6e). The rate of glycogen synthase phosphorylation was higher in the cortex $(+47 \%, p=0.042)$ and hippocampus $(+69 \%$, $p=0.007)$, but lower in the striatum $(-38 \%, p=0.042)$ of GK rats, when compared to controls. (a)

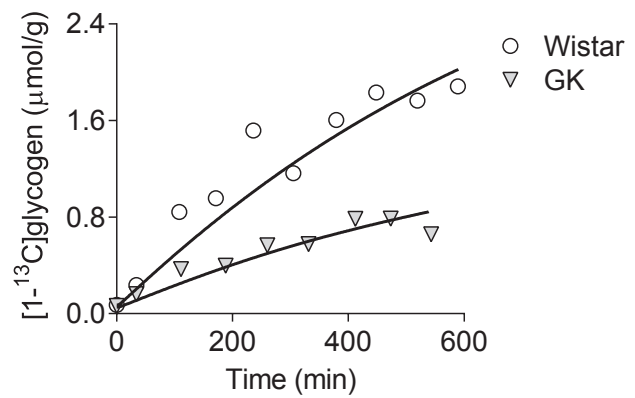

(b)

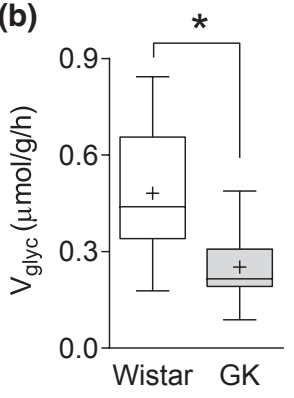

(c)

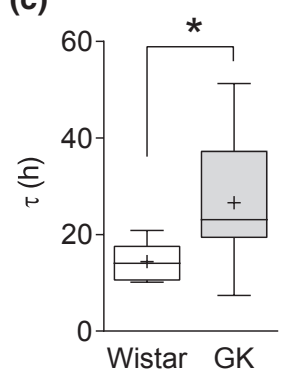

FIGURE 4 Typical brain glycogen labeling curves (a), mean $\mathrm{V}_{\text {gly }}$ (b) and $\tau$ (c) in the brain of Wistar and GK rats. ${ }^{*} p<0.05$ for GK ( $n=8$ ) versus Wistar $(n=6)$. Panels $b$ and $c$ are Tukey plots with mean value indicated by + 
(a)
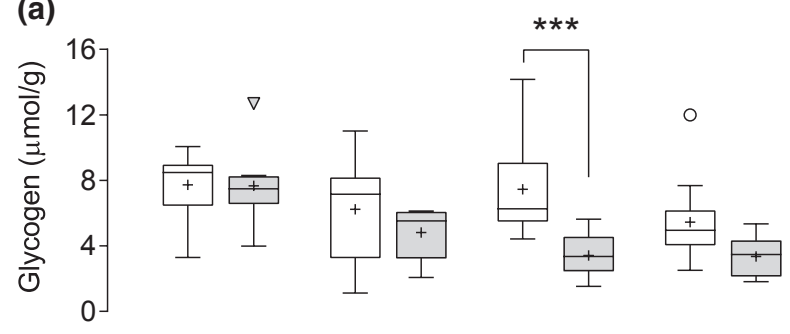

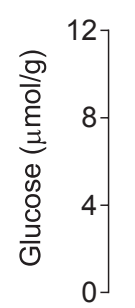
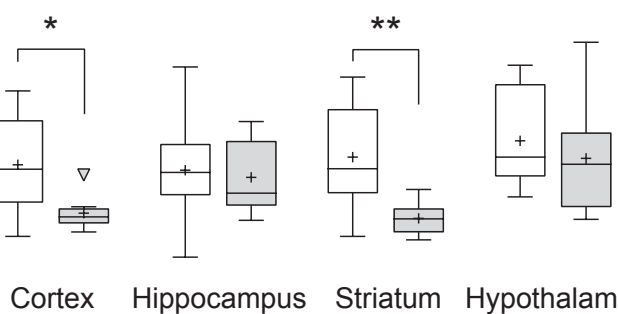

Cortex Hippocampus Striatum Hypothalamus

FIGURE 5 Regional distribution of glucose and glycogen concentrations (a) and ${ }^{13} \mathrm{C}$ fractional enrichment (b) in the brain of GK ( $n=8$ ) and Wistar $(n=6)$ rats. Results are shown in Tukey plots with mean value indicated by + and outliers by symbols (open circles for Wistar and filled triangles for GK rats). ${ }^{*} p<0.05,{ }^{* *} p<0.01,{ }^{* * *} p<0.001$ for GK versus Wistar in Holm-Sidak's posttests after significant 2 -way ANOVA

\section{4 | DISCUSSION}

The present results confirm previous findings that brain glucose utilization is reduced in the brain of diabetic GK rats, relative to controls (Girault et al., 2019), and provide evidence for impaired brain glycogen metabolism that might contribute to the learning and memory deficits in this diabetes model (Duarte et al., 2019; Li et al., 2013).

\section{1 | Brain glucose utilization}

The brain requires continuous glucose supply to sustain metabolic demands of neuronal activity. By analyzing the labeling of brain $\left[1-{ }^{13} \mathrm{C}\right]$ glucose over time, we determined a $31 \%$ reduction in $\mathrm{T}_{\max }$, the apparent maximum glucose transport rate, which is in accordance with reduced density of glucose carriers at the blood-brain-barrier (BBB). We further observed a tendency for reduced $\mathrm{CMR}_{\mathrm{glc}}(-29 \%)$ in $\mathrm{GK}$ rats relative to controls, which suggests a global glucose hypo-metabolism. A reduction in both $\mathrm{CMR}_{\mathrm{glc}}$ and $\mathrm{T}_{\max }$ resulted in identical ratio of $T_{\max }$ to $\mathrm{CMR}_{\mathrm{glc}}$, indicating that brain glucose levels are similar in GK and Wistar rats at any given glycemia (Duarte et al., 2019; Girault et al., 2019). Nevertheless, since GK rats display sustained hyperglycemia, their brains are exposed to excessive glucose levels when compared to normoglycemic rats, which may trigger a plethora of deleterious effects leading to neurodegeneration, namely through oxidative stress and non-enzymatic glycation of macromolecules (Duarte, 2015).

In GK rats, GLUT1 density was found reduced in total protein extracts of the hippocampus and hypothalamus, regions crucial for learning and memory and for regulation of glucose homeostasis, respectively. Interestingly, brain glucose content was particularly reduced in the cortex and striatum of GK rats compared to controls, while GLUT1 density was not modified by T2D in these brain areas. This clearly indicates that although total levels of (b)
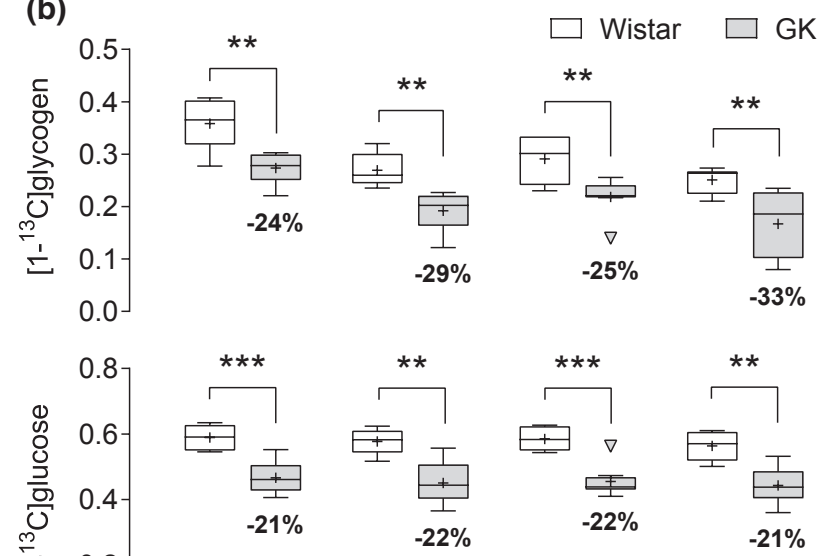

Cortex $\pm$
Striatum Hypothalamus
GLUT1 may represent the availability of carriers to mediate glucose transport, they are not indicative of BBB transport capacity. Accordingly, cerebral glucose utilization was found reduced in the brain of $d b / d b$ mice, a model of T2D, relative to controls (Garris, Williams, Coleman, \& Morgan, 1984; Vannucci, Gibbs, \& Simpson, 1997). However, Vannucci et al. reported no changes in the density of the glucose carriers GLUT1, widely expressed in the brain and the main glucose carrier at the BBB, and GLUT3, mainly located in neuronal membranes, in brain preparations obtained from $d b / d b$ mice, when compared to wild-type mice (Vannucci et al., 1997). In contrast, a recent study reported lower levels of both GLUT1 and GLUT3 in whole-brain homogenates prepared from mice exposed to a diet rich in fat and sugar for 3 months, which develop an insulin-resistant phenotype, relative to mice fed a regular chow (Kothari et al., 2017). Altogether, these observations lead us to speculate that reduced glucose transport and utilization is caused by changes in metabolic regulation according to cellular needs and adaptations to a diabetic and neurodegenerative state rather than reduced glucose carrier concentrations. Nevertheless, deficiency of GLUT1 results in reduced brain glucose uptake, and was suggested to contribute to cerebral microvascular degeneration, impaired blood flow, reduced amyloid $\beta(A \beta)$ peptide clearance, diminished neuronal activity, neurodegeneration, and behavioral deficits in an $A D$ mouse model that overexpresses the $A \beta$ precursor protein (Winkler et al., 2015). In line with this, depression of brain glucose metabolism is an early feature of AD (Duarte, 2015; Zilberter \& Zilberter, 2017), demonstrated for example by reduced density of GLUT1 and GLUT3 in the hippocampus, caudate nucleus, and neocortex (Simpson, Chundu, Davies-Hill, Honer, \& Davies, 1994), reduced binding of the non-competitive inhibitor of glucose carriers $\left[{ }^{3} \mathrm{H}\right]$ cytochalasin $B$ to neocortical and hippocampal tissue and microvessels (Kalaria \& Harik, 1989), or reduced cortical glucose transport and $\mathrm{CMR}_{\mathrm{glc}}$ (Jagust et al., 1991). 

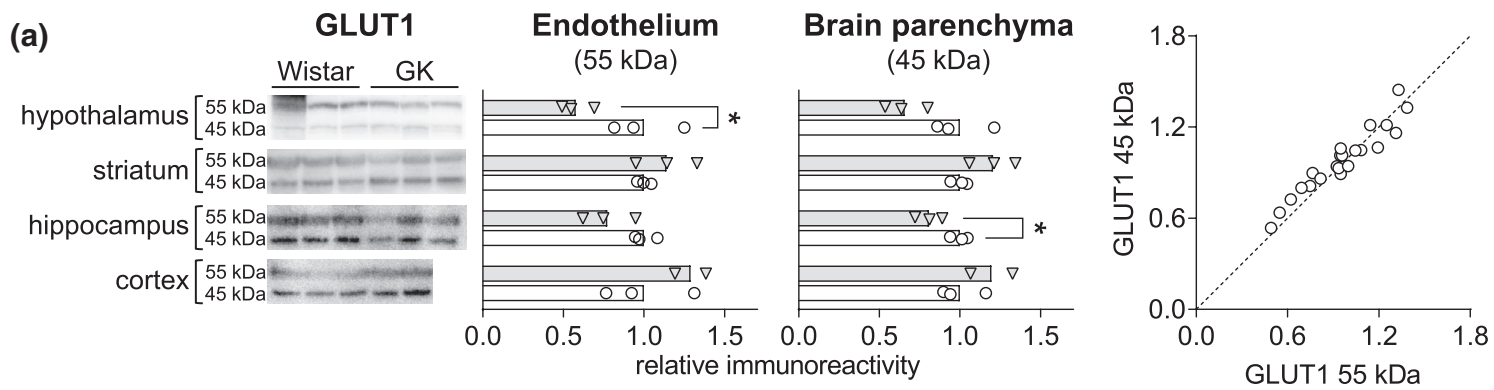

(b)

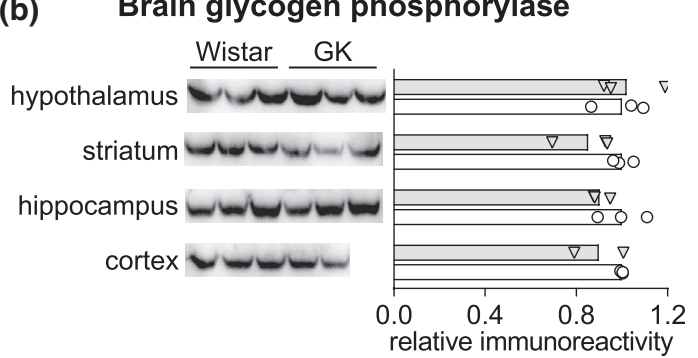

(d)

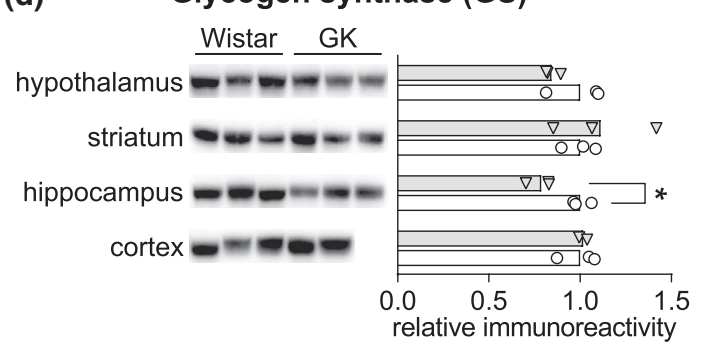

\section{(c) Muscle glycogen phosphorylase}

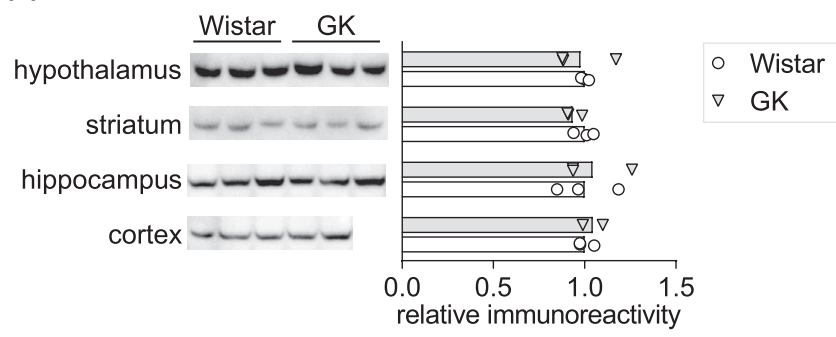

(e)

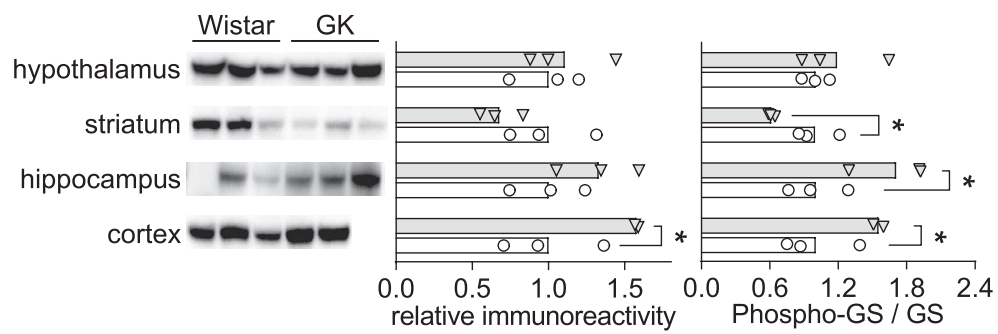

FI G URE 6 Western blot analysis of GLUT1 detected the highly glycosylated (top band, $55 \mathrm{kDa}$ ) and less glycosylated (lower band, $45 \mathrm{kDa}$ ) isoforms (a), which are present in endothelial cells and brain parenchyma, respectively. The relation between the normalized immunoreactivity of both GLUT1 forms is plotted together with the line of equality. Immunoreactivity of brain glycogen phosphorylase (b), muscle glycogen phosphorylase (c), and glycogen synthase (d) was detected at 97,94 , and $84 \mathrm{kDa}$, respectively. Panel e shows phosphoglycogen synthase immunoreactivity $(84 \mathrm{kDa})$ and the ratio of phospho- to total glycogen synthase (GS). SDS-PAGE gels were loaded with $40 \mu \mathrm{g}$ of protein for analysis of GLUT1, and with $100 \mu \mathrm{g}$ for the remaining proteins. Data points are shown in symbols (open circles for Wistar, and filled triangles for GK rats), and bars indicate the mean value of $n=2-3$, as depicted in the respective immunoreactivity pictures. The cortex from one GK rat was lost during sample preparation, thus only $n=2$ was available for SDS-PAGE. ${ }^{*} p<0.05$ from Student $t$ test comparisons between GK and Wistar

Insulin was suggested to modulate astrocytic glucose metabolism by acting in concert with the insulin-like growth factor type 1 (IGF-1), namely via a mitogen-activated protein kinase/protein kinase D pathway that controls maintenance of GLUT1 at the cell membrane (Fernandez et al., 2017). While insulin is the main regulator of peripheral glucose homeostasis, it is traditionally considered to not directly modulate global brain glucose uptake and utilization. Therefore, the extent of this insulin-IGF-1 interaction within glucose transport regulation remains unclear, although it might be of importance in neurodegenerative disorders that involve insulin resistance. For example, while hyperinsulinemia within the normal physiologic range does not impact glucose transport or $\mathrm{CMR}_{\mathrm{glc}}$ (Hasselbalch et al., 1999), insulin was shown to stimulate brain glucose metabolism in subjects with impaired glucose tolerance (Hirvonen et al., 2011). Moreover, insulin has a major role in multiple brain processes that require energy and thus insulin can indirectly modulate brain glucose homeostasis (reviewed in Duarte, 2015).

\section{2 | Brain glycogen metabolism}

Assuming that the whole glycogen pool is being metabolized at a rate of $0.48 \mu \mathrm{mol} / \mathrm{g} / \mathrm{h}$, we estimated that about $14 \mathrm{hr}$ would be necessary for the brain glycogen pool to turnover in Wistar rats. Previous ${ }^{13} \mathrm{C}$ MRS studies in rats under light $\alpha$-chloralose anesthesia, have estimated similar (Choi, Tkác, Ugurbil, \& Gruetter, 1999) or slightly faster (0.7 $\mu \mathrm{mol} / \mathrm{g} / \mathrm{h}$, van Heeswijk, Morgenthaler, Xin, \& Gruetter, 2010) glycogen turnover rates. The discrepancy on the measured turnover rates in our study and these previous publications could be caused by either the deepness of anesthesia that modulates brain activity and metabolism (Sonnay, Gruetter, \& Duarte, 2017), or the brain 
levels of insulin that might stimulate glycogen synthesis (Fernandez et al., 2017; Muhič et al., 2015). Accordingly, administration of insulin to anaesthetized rats was previously reported to increase brain glycogen levels (Morgenthaler et al., 2006). In fact, circulating levels of insulin in the present study under isoflurane were much lower than those in similar experimental conditions but under $\alpha$-chloralose anesthesia (Girault et al., 2019).

The ${ }^{13} \mathrm{C}$ incorporation from glucose into glycogen was conspicuously hampered in GK rats, relative to non-diabetic Wistar rats under identical experimental conditions. In the whole brain, glycogen synthesis rate was reduced by $48 \%$ in GK rats, relative to controls. This was further supported by the fact that the phosphorylation rate of glycogen synthase was increased in the cortex and hippocampus of GK rats, relative to controls, in line with reduced activity. However, whole-brain glycogen content was found similar. Therefore, we estimated brain glycogen turnover time to be increased by $85 \%$ in diabetic rats.

While total brain glycogen content in GK rats at the end of the hyperglycemic clamp was similar to that of Wistar rats, GK rats had lower glycogen concentration in the striatum than controls. Another rat model of T2D, the Zucker diabetic fatty rat, displayed lower brain glycogen content than lean littermates, but higher than control Sprague-Dawley rats (Sickmann et al., 2010). Then, we found that glycogen labeling from glucose was reduced in the hippocampus and the hypothalamus. Furthermore, higher phosphorylation rate of glycogen synthase in GK rats than controls is in line with reduced brain glycogen synthase activity, namely in the cortex and hippocampus. The antibody anti-phospho-glycogen synthase used in this study targets two serine phosphorylation sites, the Ser640 and Ser641, in liver and brain isoforms (according to supplier). This site is phosphorylated by the serine/threonine protein kinase glycogen synthase kinase 3 (GSK-3), as well as Ser644 and Ser648, resulting in a potent inactivating effect (Roach, 1990; Skurat \& Roach, 1995).

The hippocampus of GK rats showed prominently reduced levels of glycogen synthase. Notably, mice lacking glycogen synthase in the brain display impaired acquisition of an associative learning task, as well as impaired hippocampal long-term potentiation (Duran et al., 2013). In contrast to glycogen synthase, we found no changes in levels of glycogen phosphorylase muscle and brain isoforms. The liver isoform was not investigated due to its vestigial presence in the adult brain (Pfeiffer-Guglielmi, Bröer, Bröer, \& Hamprecht, 2000). Although it would be of interest to determine the phosphorylation rate of glycogen phosphorylase in the present study, to our knowledge there are no good antibodies against its phosphorylation sites. Nevertheless, phosphorylation is not the main regulatory mechanism of the enzyme activity. Glycogen phosphorylase is regulated allosterically by AMP and activated by phosphorylation by the phosphorylase kinase, and the brain isoform in astrocytes responds more strongly to AMP than does the muscle isoform (Bak et al., 2018; Müller, Pedersen, Walls, Waagepetersen, \& Bak, 2015). In sum, total protein level alterations (or their absence) may not directly translate into equivalent changes of enzyme activity.
Altogether, our findings suggest hampered dynamics of the brain glycogen pool, at least in the diabetic GK rat model. This has likely an impact on brain activity that depends on glycogen as an energy source, such as memory formation (Gibbs et al., 2007; Suzuki et al., 2011). Impaired learning and memory capabilities in GK rats have been associated with the degree of insulin resistance (Li et al., 2013), and it was also proposed that hippocampal insulin resistance impairs spatial learning and synaptic plasticity (Grillo et al., 2015) and is associated to astrogliosis and neuroinflammation (CalvoOchoa, Hernández-Ortega, Ferrera, Morimoto, \& Arias, 2014). Thus, we propose that hampered glycogen utilization in the diabetic brain may provide a biochemical link between cognitive impairment and insulin resistance. In line with this, noradrenergic dysfunction has been proposed to be an important component of AD (Hertz, 1989; Marien, Colpaert, \& Rosenquist, 2004; Weinshenker, 2008). Noradrenaline both modulates memory (reviewed in Alberini, Cruz, Descalzi, Bessières, \& Gao, 2018), and stimulates glycogenolysis and exerts a complex regulation of glycolysis and glycogen shunting in astrocytes (Walls, Heimbürger, Bouman, Schousboe, \& Waagepetersen, 2009 and references therein). Insulin and diabetes were suggested to modify brain noradrenaline metabolism and levels (Kwok \& Juorio, 1988; Lacković, Salković, Kuci, \& Relja, 1990; Trulson \& Himmel, 1985), but the role of the noradrenergic system on the control of glycogen metabolism in the diabetic brain remains to be investigated.

\section{3 | Limitations}

In accordance with the insulin resistance state, when GK rats were infused a ${ }^{13} \mathrm{C}$-enriched glucose solution, a strong dilution of its $\mathrm{FE}$ was observed in the plasma, when comparing with non-diabetic Wistar rats. This finding is in agreement with increased endogenous glucose production from gluconeogenesis in GK relative to Wistar rats (Sena, Barosa, Nunesa, Seiça, \& Jones, 2007), which accounts for the unlabeled glucose in the blood stream. Another difference between the experimental groups is the younger age of the Wistar rats (4-6 months old) relative to GK rats (all 6 months old). This difference was because age-matched controls are often too large to fit in the fixation system used for MRS in this study. Nevertheless, energy metabolism differences are not expected to occur in the rat brain within this age range (Dienel, 2012).

Lower isoflurane levels were needed for anesthesia of GK rats, compared to controls, and the doses of isoflurane within this range show sigmoidal responses in animal immobility tests (Saab et al., 2010). In line with this, metabolic assessments under different anesthesia doses (29\% less in GK than Wistar rats) may also bias our metabolic assessments. Any anesthesia reduces glucose uptake and consumption relative to the awake state, and we have shown that $\mathrm{T}_{\max }$ and CMRglc are similar under isoflurane and light $\alpha$-chloralose anesthesia (Duarte \& Gruetter, 2012). Therefore, the lighter anesthesia in GK than Wistar rats might result in higher metabolic activity in GK than Wistar rats, and thus lead to an underestimation of T2D-induced effects on brain glycogen metabolism. On 
the contrary, it is known that isoflurane inhibits the mitochondrial electron transport chain in a dose-dependent manner (Hanley, Ray, Brandt, \& Daut, 2002; Zimin et al., 2018). This results in increased lactate in the brain, and also in circulation. Indeed, circulating lactate was similar at baseline, but lower in GK than Wistar rats during glucose infusion (Table 1). Accordingly, isoflurane anesthesia could eventually exacerbate glucose utilization at glycolytic level to fulfil eventual needs of ATP. Being possible that these isoflurane doses have effects on some assessed parameters but not others, future studies on GK rats should consider a dose-response curve for isoflurane and the determination of minimum alveolar concentration value in these strains.

With ${ }^{13} \mathrm{C}$ MRS in vivo, we measured brain glycogen turnover using $\left[1-{ }^{13} \mathrm{C}\right]$ glucose as a precursor, which was infused for at least $8 \mathrm{hr}$. Our measurements assume that glycogen content doesn't change during the experiments and that, therefore, the appearance of $\left[1-{ }^{13} \mathrm{C}\right]$ glycogen reflects turnover, i.e., replacement of glucosyl units in glycogen without net synthesis. Although glycogen in the brain of awake rats does not change with hyperglycemia (Duarte et al., 2017), glycogen accumulation occurs upon glucose infusion under $\alpha$-chloralose anesthesia, likely mediated by insulin (Morgenthaler et al., 2006). Glucose-stimulated insulin secretion in rats under isoflurane anesthesia resulted in circulating insulin concentration (Table 1) that is one order of magnitude smaller than that under $\alpha$-chloralose anesthesia (Girault et al., 2019). One might thus speculate that brain glycogen accumulation is much smaller than that reported previously (Morgenthaler et al., 2006). Moreover, circulating insulin was similar between GK rats and controls, as well as brain glycogen levels after the hyperglycemic clamp of our experimental protocol. Therefore, the conclusion that glycogen metabolism is slower in GK than Wistar rats remains valid, despite the possibility of net glycogen synthesis to occur.

It should also be noted the small sample sizes in this study, namely $n=2-3$ for protein determination by Western blot, and $n=6-8$ for

${ }^{13} \mathrm{C}$ tracing experiments. Despite the limited number of rats used, altogether the experiments of our study point in the direction of T2D-associated alterations of glycogen metabolism.

Metabolism of glucose and glycogen is linked to glutamatergic neurotransmission (Gibbs et al., 2007; Sickmann et al., 2009; Sonnay et al., 2017). However, the present results are not sufficient to determine whether brain hypo-metabolism and reduced glycogen turnover are cause or consequence of the previously reported reduced glutamate-glutamine cycle rate in the brain of GK rats (Girault et al., 2019).

\section{DECLARATION OF TRANSPARENCY}

The authors, reviewers and editors affirm that in accordance to the policies set by the Journal of Neuroscience Research, this manuscript presents an accurate and transparent account of the study being reported and that all critical details describing the methods and results are present.

\section{ACKNOWLEDGMENTS}

The authors are grateful to Jordi Duran (Institute for Research in Biomedicine, Barcelona) for advice on Western blotting experiments for glycogen-metabolizing enzymes.

\section{CONFLICT OF INTEREST}

The authors have no conflicts of interest to declare.

\section{AUTHOR CONTRIBUTIONS}

Methodology, J.M.N.D.; Formal Analysis, A.F.S., S.S.N., J.D.N., A.G.S. and J.M.N.D.; Writing - Original Draft, A.F.S. and J.M.N.D. All authors revised and edited the manuscript.

\section{DATA AVAILABILITY}

The data that support the findings of this study are available from the corresponding author upon reasonable request.

\section{ORCID}

Helle S. Waagepetersen (iD https://orcid.org/0000-0003-4583-8379 João M. N. Duarte (iD https://orcid.org/0000-0001-5984-1574

\section{REFERENCES}

Alberini, C. M., Cruz, E., Descalzi, G., Bessières, B., \& Gao, V. (2018). Astrocyte glycogen and lactate: New insights into learning and memory mechanisms. Glia, 66(6), 1244-1262.

Bak, L. K., Walls, A. B., Schousboe, A., \& Waagepetersen, H. S. (2018), Astrocytic glycogen metabolism in the healthy and diseased brain. Journal of Biological Chemistry, 293(19), 7108-7116.

Baker, L. D., Cross, D., Minoshima, S., Belongia, D., Watson, G. S., \& Craft, S. (2011). Insulin resistance is associates with Alzheimer-like reductions in regional cerebral glucose metabolism for cognitively impaired normal adults with pre-diabetes or early type 2 diabetes. Archives of Neurology, 68, 51-57.

Baumgart, M., Snyder, H. M., Carrillo, M. C., Fazio, S., Kim, H., \& Johns, H. (2015). Summary of the evidence on modifiable risk factors for cognitive decline and dementia: A population-based perspective. Alzheimer's \& Dementia: The Journal of the Alzheimer's Association, 11(6), 718-726.

Biemann, K. (1962). Mass spectrometry. In Biemann K., (ed.), Organic chemistry applications (pp 223-227). New York, NY: McGraw.

Calì, C., Baghabra, J., Boges, D. J., Holst, G. R., Kreshuk, A., Hamprecht, F. A., ... Magistretti, P. J. (2016). Three-dimensional immersive virtual reality for studying cellular compartments in 3D models from EM preparations of neural tissues. The Journal of Comparative Neurology, 524(1), 23-38.

Calvo-Ochoa, E., Hernández-Ortega, K., Ferrera, P., Morimoto, S., \& Arias, C. (2014). Short-term high-fat-and-fructose feeding produces insulin signaling alterations accompanied by neurite and synaptic reduction and astroglial activation in the rat hippocampus. Journal of Cerebral Blood Flow and Metabolism, 34(6), 1001-1008.

Candeias, E., Duarte, A. I., Sebastião, I., Fernandes, M. A., Plácido, A. I., Carvalho, C., ... Moreira, P. I. (2016). Middle-aged diabetic females and males present distinct susceptibility to Alzheimer disease-like 
pathology. Molecular Neurobiology, 54(8), 6471-6489. https://doi. org/10.1007/s12035-016-0155-1

Cataldo, A. M., \& Broadwell, R. D. (1986). Cytochemical identification of cerebral glycogen and glucose-6-phosphatase activity under normal and experimental conditions: I. Neurons and glia. Journal of Electron Microscopy Technique, 3, 413-437.

Choi, I. Y., Seaquist, E. R., \& Gruetter, R. (2003). Effect of hypoglycemia on brain glycogen metabolism in vivo. Journal of Neuroscience Research, 72, 25-32.

Choi, I. Y., Tkác, I., Ugurbil, K., \& Gruetter, R. (1999). Noninvasive measurements of $\left[1{ }^{13} \mathrm{C}\right]$ glycogen concentrations and metabolism in rat brain in vivo. Journal of Neurochemistry, 73(3), 1300-1308.

Cruz, N. F., \& Dienel, G. A. (2002). High glycogen levels in brains of rats with minimal environmental stimuli: Implications for metabolic contributions of working astrocytes. Journal of Cerebral Blood Flow and Metabolism, 22(12), 1476-1489.

Desrois, M., Sidell, R. J., Gauguier, D., Davey, C. L., Radda, G. K., \& Clarke, K. (2004). Gender differences in hypertrophy, insulin resistance and ischemic injury in the aging type 2 diabetic rat heart. Journal of Molecular and Cellular Cardiology, 37(2), 547-555.

Dienel, G. A. (2012). Fueling and imaging brain activation. ASN Neuro, $4,5$.

Duarte, J. M. N. (2015). Metabolic alterations associated to brain dysfunction in diabetes. Aging and Disease, 6(5), 304-321.

Duarte, J. M. N., Carvalho, R. A., Cunha, R. A., \& Gruetter, R. (2009). Caffeine consumption attenuates neurochemical modifications in the hippocampus of streptozotocin-induced diabetic rats. Journal of Neurochemistry, 111, 368-379.

Duarte, J. M. N., Cunha, R. A., \& Carvalho, R. A. (2007). Different metabolism of glutamatergic and GABAergic compartments in superfused hippocampal slices characterized by nuclear magnetic resonance spectroscopy. Neuroscience, 144(4), 1305-1313.

Duarte, J. M. N., \& Gruetter, R. (2012). Characterization of cerebral glucose dynamics in vivo with a four-state conformational model of transport at the blood-brain barrier. Journal of Neurochemistry, 121(3), 396-406.

Duarte, J. M. N., Lanz, B., \& Gruetter, R. (2011). Compartmentalized cerebral metabolism of $\left[1,6-{ }^{13} \mathrm{C}\right]$ glucose determined by in vivo ${ }^{13} \mathrm{C} N \mathrm{NMR}$ spectroscopy at 14.1 T. Frontiers in Neuroenergetics, 6, 3.

Duarte, J. M. N., Morgenthaler, F. D., \& Gruetter, R. (2017). Glycogen supercompensation in the rat brain after acute hypoglycemia is independent of glucose levels during recovery. Neurochemical Research, 42(6), 1629-1635.

Duarte, J. M. N., Skoug, C., Silva, H. B., Carvalho, R. A., Gruetter, R., \& Cunha, R. A. (2019). Impact of caffeine consumption on type 2 diabetes-induced spatial memory impairment and neurochemical alterations in the hippocampus. Frontiers in Neuroscience, 12, 1015.

Duran, J., Saez, I., Gruart, A., Guinovart, J. J., \& Delgado-García, J. M. (2013). Impairment in long-term memory formation and learningdependent synaptic plasticity in mice lacking glycogen synthase in the brain. Journal of Cerebral Blood Flow and Metabolism, 33(4), 550-556.

Faul, F., Erdfelder, E., Buchner, A., \& Lang, A.-G. (2009). Statistical power analyses using G*Power 3.1: Tests for correlation and regression analyses. Behavior Research Methods, 41, 1149-1160.

Fernandez, A. M., Hernandez-Garzón, E., Perez-Domper, P., PerezAlvarez, A., Mederos, S., Matsui, T., ... Torres Aleman, I. (2017). Insulin regulates astrocytic glucose handling through cooperation with IGF-I. Diabetes, 66(1), 64-74.

Frisardi, V., Solfrizzi, V., Seripa, D., Capurso, C., Santamato, A., Sancarlo, D., ... Panza, F. (2010). Metabolic-cognitive syndrome: A cross-talk between metabolic syndrome and Alzheimer's disease. Ageing Research Reviews, 9(4), 399-417.

Garris, D. R., Williams, S. K., Coleman, D. L., \& Morgan, C. R. (1984). Glucose utilization by the mouse brain: Influence of age and diabetes. Brain Research, 317(2), 141-146.
Genda, E. N., Jackson, J. G., Sheldon, A. L., Locke, S. F., Greco, T. M., O'Donnell, J. C., ... Robinson, M. B. (2011). Co-compartmentalization of the astroglial glutamate transporter, GLT-1, with glycolytic enzymes and mitochondria. Journal of Neuroscience, 31(50), 18275-18288.

Gibbs, M. E., Anderson, D. G., \& Hertz, L. (2006). Inhibition of glycogenolysis in astrocytes interrupts memory consolidation in young chickens. Glia, 54(3), 214-222.

Gibbs, M. E., Lloyd, H. G., Santa, T., \& Hertz, L. (2007). Glycogen is a preferred glutamate precursor during learning in 1-day-old chick: Biochemical and behavioral evidence. Journal of Neuroscience Research, 85(15), 3326-3333.

Girault, F. M., Sonnay, S., Gruetter, R., \& Duarte, J. M. N. (2019). Alterations of brain energy metabolism in type 2 diabetic GotoKakizaki rats measured in vivo by $13 \mathrm{C}$ magnetic resonance spectroscopy. Neurotoxicity Research. In press. https://doi.org/10.1007/ s12640-017-9821-y

Goto, Y., Kakizaki, M., \& Masaki, N. (1976). Production of spontaneous diabetic rats by repetition of selective breeding. Tohoku Journal of Experimental Medicine, 119(1), 85-90.

Grillo, C. A., Piroli, G. G., Lawrence, R. C., Wrighten, S. A., Green, A. J., Wilson, S. P., ... Reagan, L. P. (2015). Hippocampal insulin resistance impairs spatial learning and synaptic plasticity. Diabetes, 64(11), 3927-3936.

Hanley, P. J., Ray, J., Brandt, U., \& Daut, J. (2002). Halothane, isoflurane and sevoflurane inhibit NADH:Ubiquinone oxidoreductase (complex I) of cardiac mitochondria. Journal of Physiology, 544(3), 687-693.

Hasselbalch, S. G., Knudsen, G. M., Videbaek, C., Pinborg, L. H., Schmidt, J. F., Holm, S., \& Paulson, O. B. (1999). No effect of insulin on glucose blood-brain barrier transport and cerebral metabolism in humans. Diabetes, 48(10), 1915-1921.

Hertz, L. (1989). Is Alzheimer's disease an anterograde degeneration, originating in the brainstem, and disrupting metabolic and functional interactions between neurons and glial cells? Brain Research. Brain Research Reviews, 14(4), 335-353.

Herzog, R. I., Chan, O., Yu, S., Dziura, J., McNay, E. C., \& Sherwin, R. S. (2008). Effect of acute and recurrent hypoglycemia on changes in brain glycogen concentration. Endocrinology, 149, 1499-1504.

Hirvonen, J., Virtanen, K. A., Nummenmaa, L., Hannukainen, J. C., Honka, M. J., Bucci, M., ... Nuutila, P. (2011). Effects of insulin on brain glucose metabolism in impaired glucose tolerance. Diabetes, 60(2), 443-447.

Holman, G. D., Kozka, I. J., Clark, A. E., Flower, C. J., Saltis, J., Habberfield, A. D., ... Cushman, S. W. (1990). Cell surface labeling of glucose transporter isoform GLUT4 by bis-mannose photolabel. Correlation with stimulation of glucose transport in rat adipose cells by insulin and phorbol ester. Journal of Biological Chemistry, 265(30), 18172-18179.

Jackson, S. J., Waterhouse, J. S., \& Bluck, L. J. (2007). A single glucose derivative suitable for gas chromatography/mass spectrometry and gas chromatography/combustion/isotope ratio mass spectrometry. Rapid Communications in Mass Spectrometry, 21(18), 3123-3128.

Jagust, W. J., Seab, J. P., Huesman, R. H., Valk, P. E., Mathis, C. A., Reed, B. R., ... Budinger, T. F. (1991). Diminished glucose transport in Alzheimer's disease: Dynamic PET studies. Journal of Cerebral Blood Flow and Metabolism, 11(2), 323-330.

Kalaria, R. N., \& Harik, S. I. (1989). Reduced glucose transporter at the blood-brain barrier and in cerebral cortex in Alzheimer disease. Journal of Neurochemistry, 53(4), 1083-1088.

Koizumi, J., \& Shiraishi, H. (1970). Ultrastructural appearance of glycogen in the hypothalamus of the rabbit following chlorpromazine administration. Experimental Brain Research, 10(3), 276-282.

Kong, J., Shepel, P. N., Holden, C. P., Mackiewicz, M., Pack, A. I., \& Geiger, J. D. (2002). Brain glycogen decreases with increased periods of wakefulness: Implications for homeostatic drive to sleep. Journal of Neuroscience, 22(13), 5581-5587. 
Kothari, V., Luo, Y., Tornabene, T., O'Neill, A. M., Greene, M. W., Geetha, T., \& Babu, J. R. (2017). High fat diet induces brain insulin resistance and cognitive impairment in mice. Biochimica et Biophysica Acta, 1863(2), 499-508.

Kwok, R. P., \& Juorio, A. V. (1988). Effects of insulin on rat brain noradrenaline. Neurochemical Research, 13(9), 887-892.

Lacković, Z., Salković, M., Kuci, Z., \& Relja, M. (1990). Effect of long-lasting diabetes mellitus on rat and human brain monoamines. Journal of Neurochemistry, 54(1), 143-147.

Li, X. H., Xin, X., Wang, Y., Wu, J. Z., Jin, Z. D., Ma, L. N., ... Jin, M. W. (2013). Pentamethylquercetin protects against diabetes-related cognitive deficits in diabetic Goto-Kakizaki rats. Journal of Alzheimer's Disease, 34(3), 755-767.

Marien, M. R., Colpaert, F. C., \& Rosenquist, A. C. (2004). Noradrenergic mechanisms in neurodegenerative diseases: A theory. Brain Research. Brain Research Reviews, 45(1), 38-78.

Morgenthaler, F. D., Koski, D. M., Kraftsik, R., Henry, P. G., \& Gruetter, R. (2006). Biochemical quantification of total brain glycogen concentration in rats under different glycemic states. Neurochemistry International, 48, 616-622.

Morgenthaler, F. D., Lanz, B. R., Petit, J. M., Frenkel, H., Magistretti, P. J., \& Gruetter, R. (2009). Alteration of brain glycogen turnover in the conscious rat after $5 \mathrm{~h}$ of prolonged wakefulness. Neurochemistry International, 55(1-3), 45-51.

Muhič, M., Vardjan, N., Chowdhury, H. H., Zorec, R., \& Kreft, M. (2015). Insulin and insulin-like growth factor 1 (IGF-1) modulate cytoplasmic glucose and glycogen levels but not glucose transport across the membrane in astrocytes. Journal of Biological Chemistry, 290(17), 11167-11176.

Müller, M. S., Pedersen, S. E., Walls, A. B., Waagepetersen, H. S., \& Bak, L. K. (2015). Isoform-selective regulation of glycogen phosphorylase by energy deprivation and phosphorylation in astrocytes. Glia, 63(1), 154-162.

Nelson, S. R., Schulz, D. W., Passonneau, J. V., \& Lowry, O. H. (1968). Control of glycogen levels in brain. Journal of Neurochemistry, 15 , 1271-1279.

Newman, L. A., Korol, D. L., \& Gold, P. E. (2011). Lactate produced by glycogenolysis in astrocytes regulates memory processing. PLoS ONE, 6(12), e28427.

Oe, Y., Baba, O., Ashida, H., Nakamura, K. C., \& Hirase, H. (2016). Glycogen distribution in the microwave-fixed mouse brain reveals heterogeneous astrocytic patterns. Glia, 64(9), 1532-1545.

Pfeiffer-Guglielmi, B., Bröer, S., Bröer, A., \& Hamprecht, B. (2000). Isozyme pattern of glycogen phosphorylase in the rat nervous system and rat astroglia-rich primary cultures: Electrophoretic and polymerase chain reaction studies. Neurochemical Research, 25(11), 1485-1491.

Phelps, C. H. (1972). Barbiturate-induced glycogen accumulation in brain An electron microscopic study. Brain Research, 39(1), 225-234.

Roach, P. J. (1990). Control of glycogen synthase by hierarchal protein phosphorylation. The FASEB Journal, 4(12), 2961-2968.

Saab, B. J., Maclean, A. J., Kanisek, M., Zurek, A. A., Martin, L. J., Roder, J. C., \& Orser, B. A. (2010). Short-term memory impairment after isoflurane in mice is prevented by the $\alpha 5 \gamma$-aminobutyric acid type $\mathrm{A}$ receptor inverse agonist L-655,708. Anesthesiology, 113(5), 1061-1071.

Sena, C. M., Barosa, C., Nunesa, E., Seiça, R., \& Jones, J. G. (2007). Sources of endogenous glucose production in the Goto-Kakizaki diabetic rat. Diabetes \& Metabolism, 33(4), 296-302.

Shulman, R. G., Hyder, F., \& Rothman, D. L. (2001). Cerebral energetics and the glycogen shunt: Neurochemical basis of functional imaging. Proceedings of the National Academy of Sciences of the United States of America, 98(11), 6417-6422.

Sickmann, H. M., Waagepetersen, H. S., Schousboe, A., Benie, A. J., \& Bouman, S. D. (2010). Obesity and type 2 diabetes in rats are associated with altered brain glycogen and amino-acid homeostasis. Journal of Cerebral Blood Flow and Metabolism, 30(8), 1527-1537.
Sickmann, H. M., Walls, A. B., Schousboe, A., Bouman, S. D., \& Waagepetersen, H. S. (2009). Functional significance of brain glycogen in sustaining glutamatergic neurotransmission. Journal of Neurochemistry, 109(Suppl 1), 80-86.

Simpson, I. A., Carruthers, A., \& Vannucci, S. J. (2007). Supply and demand in cerebral energy metabolism: The role of nutrient transporters. Journal of Cerebral Blood Flow and Metabolism, 27(11), 1766-1791.

Simpson, I. A., Chundu, K. R., Davies-Hill, T., Honer, W. G., \& Davies, P. (1994). Decreased concentrations of GLUT1 and GLUT3 glucose transporters in the brains of patients with Alzheimer's disease. Annals of Neurology, 35(5), 546-551.

Sinadinos, C., Valles-Ortega, J., Boulan, L., Solsona, E., Tevy, M. F., Marquez, M., ... Guinovart, J. J. (2014). Neuronal glycogen synthesis contributes to physiological aging. Aging Cell, 13(5), 935-945.

Skurat, A. V., \& Roach, P. J. (1995). Phosphorylation of sites 3a and 3b (Ser640 and Ser644) in the control of rabbit muscle glycogen synthase. Journal of Biological Chemistry, 270(21), 12491-12497.

Sonnay, S., Gruetter, R., \& Duarte, J. M. N. (2017). How energy metabolism supports cerebral function: Insights from ${ }^{13} \mathrm{C}$ magnetic resonance studies in vivo. Frontiers in Neuroscience, 11, 288.

Spauwen, P. J., Köhler, S., Verhey, F. R., Stehouwer, C. D., \& van Boxtel, M. P. (2013). Effects of type 2 diabetes on 12-year cognitive change: Results from the Maastricht Aging Study. Diabetes Care, 36(6), 1554-1561.

Steculorum, S. M., Solas, M., \& Brüning, J. C. (2014). The paradox of neuronal insulin action and resistance in the development of aging-associated diseases. Alzheimer's \& Dementia: The Journal of the Alzheimer's Association, 10(1 Suppl), S3-11.

Suzuki, A., Stern, S. A., Bozdagi, O., Huntley, G. W., Walker, R. H., Magistretti, P. J., \& Alberini, C. M. (2011). Astrocyte-neuron lactate transport is required for long-term memory formation. Cell, 144(5), 810-823. https://doi.org/10.1016/j.cell.2011.02.018

Swanson, R. A., Morton, M. M., Sagar, S. M., \& Sharp, F. R. (1992). Sensory stimulation induces local cerebral glycogenolysis: Demonstration by autoradiography. Neuroscience, 51(2), 451-461.

Swanson, R. A., Sagar, S. M., \& Sharp, F. R. (1989). Regional brain glycogen stores and metabolism during complete global ischaemia. Neurological Research, 11(1), 24-28.

Trulson, M. E., \& Himmel, C. D. (1985). Effects of insulin and streptozotocin-induced diabetes on brain norepinephrine metabolism in rats. Journal of Neurochemistry, 44(6), 1873-1876.

van Heeswijk, R. B., Morgenthaler, F. D., Xin, L., \& Gruetter, R. (2010). Quantification of brain glycogen concentration and turnover through localized ${ }^{13} \mathrm{C}$ NMR of both the $\mathrm{C}_{1}$ and $\mathrm{C}_{6}$ resonances. NMR in Biomedicine, 23(3), 270-276.

van Heeswijk, R. B., Pilloud, Y., Morgenthaler, F. D., \& Gruetter, R. (2012), A comparison of in vivo ${ }^{13} \mathrm{C}$ MR brain glycogen quantification at 9.4 and 14.1 T. Magnetic Resonance in Medicine, 67, 1523-1527.

Vannucci, S. J., Gibbs, E. M., \& Simpson, I. A. (1997). Glucose utilization and glucose transporter proteins GLUT-1 and GLUT-3 in brains of diabetic (db/db) mice. American Journal of Physiology, 272(2 Pt 1), E267-E274.

Walls, A. B., Bak, L. K., Sonnewald, U., Schousboe, A., \& Waagepetersen, H. S. (2014). Metabolic mapping of astrocytes and neurons in culture using stable isotopes and gas chromatography-mass spectroscopy (GC-MS). In J. Hirrlinger \& H. S. Waagepetersen (Eds.),Brain energy metabolism, neuromethods (vol. 90, pp. 73-105). New York, NY: Springer Science+Business Media.

Walls, A. B., Heimbürger, C. M., Bouman, S. D., Schousboe, A., \& Waagepetersen, H. S. (2009). Robust glycogen shunt activity in astrocytes: Effects of glutamatergic and adrenergic agents. Neuroscience, 158(1), 284-292.

Weinshenker, D. (2008). Functional consequences of locus coeruleus degeneration in Alzheimer's disease. Current Alzheimer Research, 5(3), 342-345. 
Winkler, E. A., Nishida, Y., Sagare, A. P., Rege, S. V., Bell, R. D., Perlmutter, D., ... Zlokovic, B. V. (2015). GLUT1 reductions exacerbate Alzheimer's disease vasculo-neuronal dysfunction and degeneration. Nature Neuroscience, 18(4), 521-530.

Xiang, Q., Zhang, J., Li, C. Y., Wang, Y., Zeng, M. J., Cai, Z. X., ... Li, X. H. (2015). Insulin resistance-induced hyperglycemia decreased the activation of Akt/CREB in hippocampus neurons: Molecular evidence for mechanism of diabetes-induced cognitive dysfunction. Neuropeptides, 54, 9-15.

Zilberter, Y., \& Zilberter, M. (2017). The vicious circle of hypometabolism in neurodegenerative diseases: Ways and mechanisms of metabolic correction. Journal of Neuroscience Research, 95(11), 2217-2235.

Zimin, P. I., Woods, C. B., Kayser, E. B., Ramirez, J. M., Morgan, P. G., \& Sedensky, M. M. (2018). Isoflurane disrupts excitatory neurotransmitter dynamics via inhibition of mitochondrial complex I. British Journal of Anaesthesia, 120(5), 1019-1032.

\section{SUPPORTING INFORMATION}

Additional supporting information may be found online in the Supporting Information section at the end of the article.

Transparent Science Questionnaire for Authors.

How to cite this article: Soares AF, Nissen JD, Garcia-Serrano AM, Nussbaum SS, Waagepetersen HS, Duarte JMN.

Glycogen metabolism is impaired in the brain of male type 2 diabetic Goto-Kakizaki rats. J Neuro Res. 2019;97:1004-1017. https://doi.org/10.1002/jnr.24437 